\title{
Fusobacterium nucleatum promotes liver metastasis in colorectal cancer by regulating the hepatic immune niche and altering gut microbiota
}

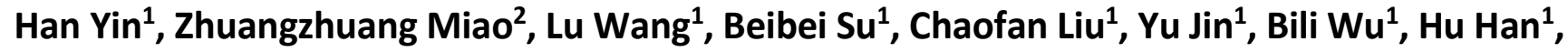 \\ Xianglin Yuan ${ }^{1}$ \\ ${ }^{1}$ Department of Oncology, Tongji Hospital, Huazhong University of Science and Technology, Wuhan, China \\ ${ }^{2}$ Department of Neurosurgery, Tongji Hospital, Huazhong University of Science and Technology, Wuhan, China
}

Correspondence to: Xianglin Yuan; email: yuanxianglin@hust.edu.cn

Keywords: Fusobacterium nucleatum, colorectal cancer, metastasis, immune microenvironment, gut microbiota

Received: September 17, 2021 Accepted: December 11, $2021 \quad$ Published:

Copyright: (C) 2022 Yin et al. This is an open access article distributed under the terms of the Creative Commons Attribution License (CC BY 3.0), which permits unrestricted use, distribution, and reproduction in any medium, provided the original author and source are credited.

\section{ABSTRACT}

Liver metastasis is the major cause of death in colorectal cancer (CRC) patients. Nevertheless, the underlying mechanisms remain unknown. Gut microbiota intricately affect the initiation and progression of CRC by instigating immune response through the secretion of pro-inflammatory cytokines. In this study, we investigated the contribution of Fusobacterium nucleatum (F.nucleatum) to the microbiota-liver axis of CRC in mice, focusing on the correlation between liver immunity and gut microbiota alterations. When $F$. nucleatum was orally administered to mice, CRC liver metastasis was evidently exaggerated and accompanied by noticeable deleterious effects on body weight, cecum weight, and overall survival time. Further evaluation of the immune response and cytokine profiles revealed a substantial increase in the levels of pro-inflammatory cytokines such as IL6, IL12, IL9, IL17A, CXCL1, MCP-1, TNF- $\alpha$, and IFN- $\gamma$ in the plasma of mice treated with $F$. nucleatum as compared to that in the untreated control mice. Besides, hepatic immune response was also modulated by recruitment of myeloid-derived suppressor cells, reduction in the infiltration of natural killer (NK) and T helper17 (Th17) cells, as well as increase in regulatory $T$ cell accumulation in the liver. Additionally, sustained $F$. nucleatum exposure abridged the murine gut microbiota diversity, inducing an imbalanced and restructured intestinal microflora. In particular, the abundance of CRC-promoting bacteria such as Enterococcus and Escherichia/Shigella was evidently elevated post $F$. nucleatum treatment. Thus, our findings suggest that $F$. nucleatum might be an important factor involved in promoting CRC liver metastasis by triggering of liver immunity through the regulation of gut microbiota structure and composition.

\section{INTRODUCTION}

CRC is the third-leading cause of cancer-related deaths worldwide [1]. More than $50 \%$ of patients progress to metastasis during the course of this disease, making it the leading cause of CRC-associated deaths [2]. Liver is the primary target organ for distant metastasis in CRC patients. Approximately $25 \%$ of patients present with synchronous liver metastases at initial diagnosis [3]. However, only less than $15 \%$ of patients with CRC liver metastasis (CRLM) meet the criteria for surgical resection. Nevertheless, even after surgery, relapses generally occur in $75 \%$ of patients, with approximately half of them occurring in the liver leading to high mortality in CRC patients [4]. Although chemotherapy and targeted medicines for unresectable CRLM have made tremendous advances for decades, its prognosis remains poor [5, 6]. Hence, elucidating the underlying mechanism of CRLM will be beneficial for the development of efficacious novel CRC therapeutics. 
The gut commensal microbiota is a complex system that regulates the host immunity. Modulation of intestinal microbiota composition has been documented to contribute toward the disruption of the ecosystem, favoring abnormal immune activation to support or prevent tumor growth [7]. In fact, both specific bacteria and dysbacteriosis have indicated a complex link with colorectal carcinogenesis through the activation of immunity $[8,9]$. Dysregulation of gut microbiota has been reported to instigate a pro-inflammatory microenvironment by regulating the cytokine activity and its interaction with the immune system, thereby promoting tumor growth [10].

In terms of CRLM, the liver is exposed to gut metabolites and components through the portal vein and enterohepatic circulation, which is intensely affected by gut microbiota in hepatocellular cancer [11] and hepatic metastasis [12]. Numerous studies have demonstrated that the gut microbiota mediates the secretion of inflammatory cytokines such as IL6, IL12, IL17, tumor necrosis factor- $\alpha$ (TNF- $\alpha)$, and interferon- $\gamma($ IFN- $\gamma)$ to form an immune suppressive microenvironment in the liver to facilitate CRLM progression [13, 14]. Moreover, gut microbiota modulate the accumulation of hepatic natural killer T(NKT) cells in a chemokine (C$\mathrm{X}-\mathrm{C}$ motif) ligand 16-dependent manner by affecting bile acid metabolism [14]. Sodium butyrate is also found to regulate the gut microbiome and the balance between regulatory $\mathrm{T}$ (Treg) and Th17 cells in the murine liver [13]. In particular, studies have reported that $F$. nucleatum enhances CRC invasion, proliferation, and recurrence by activating pro-inflammatory pathways $[15,16]$, triggering mucosa-associated inflammation [17] and blocking the cytotoxic antitumor activity of $\mathrm{T}$ cells [18] and NK cells [19]. Furthermore, it has been evidently shown that $F$. nucleatum can be detected in liver metastases by fluorescence in situ hybridization and that antibiotics can inhibit the growth of $F$. nucleatum-infected tumors, suggesting that $F$. nucleatum facilitates cancer cell migration and proliferation in CRC [20].

Nevertheless, the effects of $F$. nucleatum on the immune response in relation to inflammatory cytokines in the liver, as well as the changes in the structure and composition of gut microbiota have not been comprehensively investigated. Hence, this study aimed to evaluate the influence of $F$. nucleatum on the diversity and composition of gut microbiome using a murine model. Further, the effect of $F$. nucleatum-mediated gut microbiome alterations on the innate and adaptive immune response leading to augmented hepatic metastases were also investigated, thus providing potent novel insights for developing an effective treatment strategy for CRLM.

\section{RESULTS}

\section{Administration of $F$. nucleatum promotes liver metastasis of CRC in mice}

To investigate the effect of $F$. nucleatum on the phenomenon of CRLM, $1 \times 10^{6}$ CT26-Luc cells were injected beneath the splenic capsule of mice to establish a liver metastasis model after a 4-week administration of either F. nucleatum or PBS (Figure 1A). Subsequent analyses revealed that the mice treated with $F$. nucleatum demonstrated significant weight loss at the second week post tumor injection in addition to a median survival time of less than 40 days as compared to the median survival time of 60 days in mice treated with PBS (Figure 1B, 1C).

To further determine whether $F$. nucleatum infection promotes CRLM, we used an in vivo optical imaging system to monitor the liver metastases of CT26-Luc cells using a murine CRC model. Our results showed that on the $28^{\text {th }}$ day post establishment of the model, CT26-Luc cells were found to be successfully seeded in the spleens of mice (Figure 2A). Furthermore, the liver metastatic rate in PBS-treated mice $(\mathrm{n}=4)$ and $F$. nucleatum-treated mice $(\mathrm{n}=10)$ were determined to be $26.67 \%$ and $66.67 \%$ respectively (Figure 2F). Subsequent region of interest (ROI) analysis of the optical in vivo imaging studies showed that the mean relative luminescence count (number of photons emitted per second) in the livers of $F$. nucleatum-treated mice was significantly higher than that in the PBS-treated mice (Figure 2B). Moreover, enhanced metastases and a higher tumor burden were observed in mice after $F$. nucleatum treatment as compared to that in PBStreated mice (Figure 2C, 2D). Particularly, the metastatic liver weight of $F$. nucleatum-treated mice was determined to be markedly higher than that of the control group (Figure 2E).

\section{$F$. nucleatum augments the levels of inflammatory cytokines in plasma}

To determine the effect of $F$. nucleatum administration on the levels of inflammatory cytokines in the plasma of mice, a cytokine antibody array was employed. The results revealed that the plasma from the $F$. nucleatum group exhibited higher levels of pro-inflammatory cytokines as compared to that from the PBSadministered group. Previous studies have illustrated that Fusobacterium-enriched adenoma cases exhibit increased secretion of inflammatory cytokines [21]. Consistent with this finding, our study also demonstrated that the $F$. nucleatum-treated mice exhibit significantly increased levels of the pro-inflammatory cytokines such as IFN- $\gamma$, TNF- $\alpha$, IL6, IL12, IL17A, 
chemokine (C-X-C motif) ligand 1 (CXCL1), IL9, macrophage chemoattractant protein-1(MCP-1), and Eotaxin as compared to the PBS-treated mice (Figure $3 \mathrm{~A}-3 \mathrm{I})$. In contrast, there were no significant changes in the secretion of IL10 and IL1 $\alpha$ (Figure 3J, 3K).

\section{F. nucleatum aggravates CRLM by remodeling the liver immune microenvironment}

To explore the immune mechanisms of tumor progression, we further evaluated the impact of $F$. nucleatum on the liver immune microenvironment. The analyses of the murine livers and spleens post treatment with PBS or $F$. nucleatum revealed that $F$. nucleatum-treated mice exhibit elevated peripheral and hepatic myeloid-derived suppressor cell (MDSC) $\left(\mathrm{CD} 11 \mathrm{~b}^{+} \mathrm{Gr}-1^{+}\right)$infiltration (Figure 4A), but decreased $\mathrm{NK}\left(\mathrm{CD}^{-} \mathrm{CD}^{-} \mathrm{b}^{+}\right)$as well as $\mathrm{CD}^{+}, \mathrm{CD}^{+}$, and $\mathrm{CD}^{+} \mathrm{T}$ cells in their livers as compared to the PBS-administered control mice (Figure 4B-4D). However, F. nucleatum exposure had no effect on NKT cells $\left(\mathrm{CD}^{+} \mathrm{CD}^{4} 9 \mathrm{~b}^{+}\right)$(Figure $\left.4 \mathrm{~B}\right)$ or tumorassociated macrophages (TAM) $\left(\mathrm{CD} 11 \mathrm{~b}^{+} \mathrm{F} 4 / 80^{+}\right)$ (Figure 4E) in either the spleen or liver as compared to the PBS treatment of mice. Furthermore, the reduction of NK cells (Figure 4B) and $\mathrm{CD}^{+} \mathrm{T}$ cells (Figure 4D) was not detected in the spleens of $F$. nucleatum-treated mice, suggesting a liver-specific effect.
The Treg/Th17 cells balance mediates the pro- and anti-tumor immunity of CRC. To investigate whether $F$. nucleatum can modulate the tumor microenvironment (TME), Tregs $\left(\mathrm{CD} 4{ }^{+} \mathrm{Foxp}^{+}\right)$and Th17 $\left(\mathrm{IL}^{+} 7^{+} \mathrm{CD} 4^{+}\right)$ cells were detected in murine livers and spleens post establishment of CRC model in the $F$. nucleatum or PBS-administered mice. The results revealed that Treg lymphocytes were significantly elevated in the $F$. nucleatum group as compared to that in the PBSadministered group (Figure 4F), which corroborates with the tumor promoting role of Tregs in CRC progression [22]. Contrastingly, the Th17 cells were found to be reduced in livers but not spleen of mice after $F$. nucleatum administration in the liver as compared to those administered with PBS as control (Figure 4F). These results demonstrated that $F$. nucleatum plays a potent role in regulating the abundance of Tregs and Th17 cells to modulate antitumor immunity in murine livers.

\section{F. nucleatum-induced intestinal microbial dysbiosis is involved in the development of CRLM}

To investigate the influence of gut microbiota changes related to $F$. nucleatum administration on the manifestation of CRLM, we aseptically collected stool samples from the distal rectum, immediately after euthanizing mice with established CRC treated with either $F$. nucleatum or PBS, for 16S rRNA gene

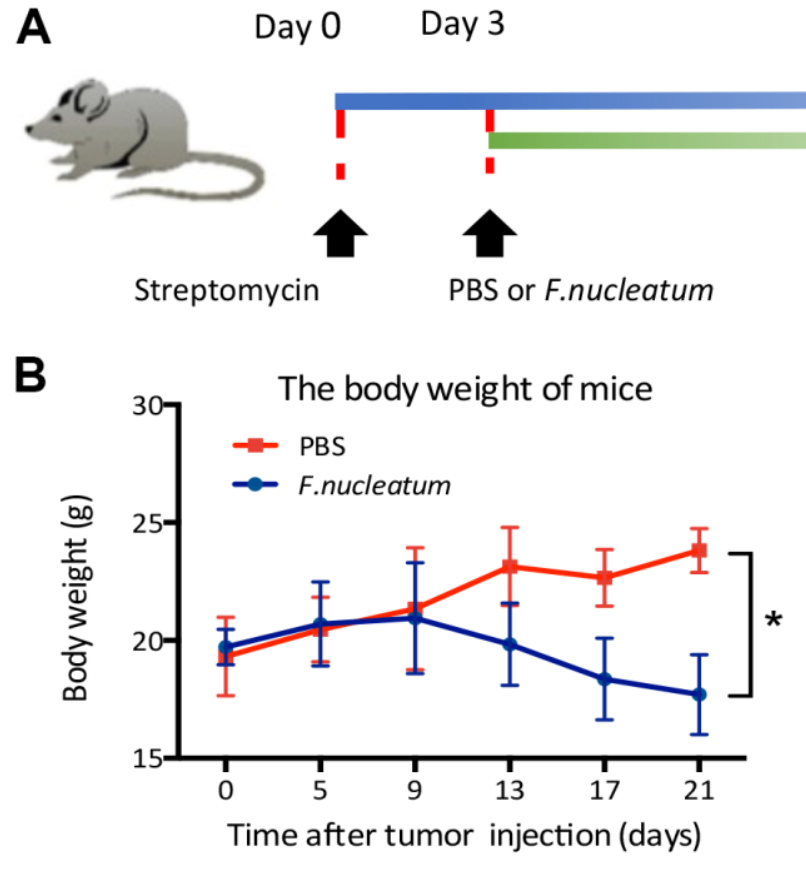

Day 31

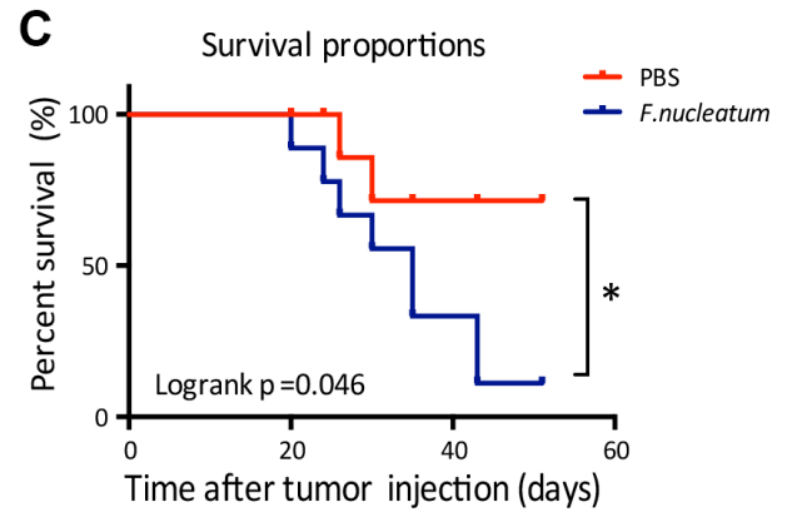

Figure 1. Fusobacterium nucleatum affects the weight and survival time of mice in a model of liver metastasis of colorectal cancer. (A) Schematic of the experimental setup. (B, C) The effects of $F$. nucleatum administration on body weight (B) and survival time (C) ( $n=15$ per group). 
A

๓ุ
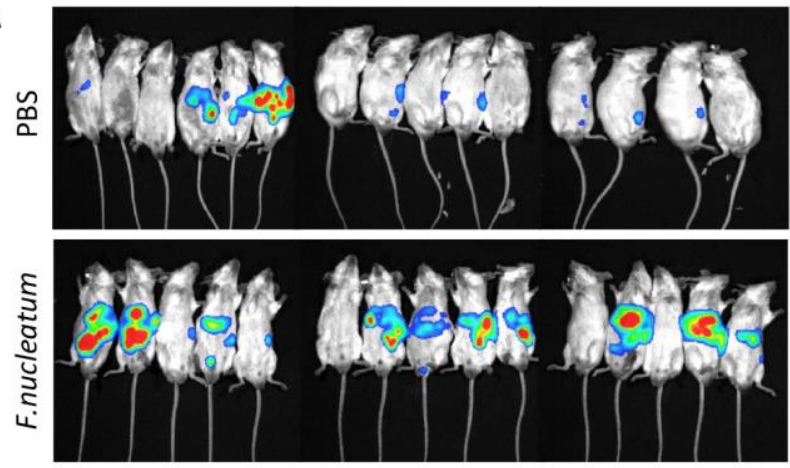

C
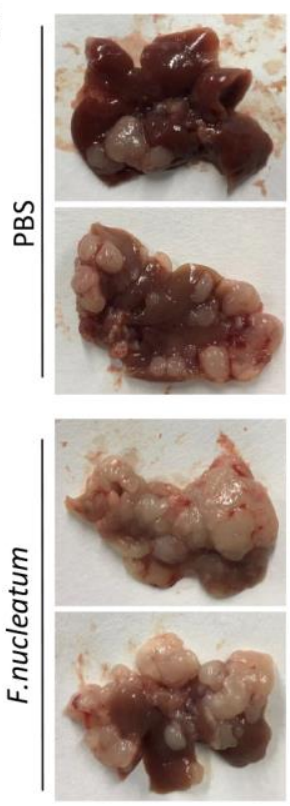

$\mathbf{E}$
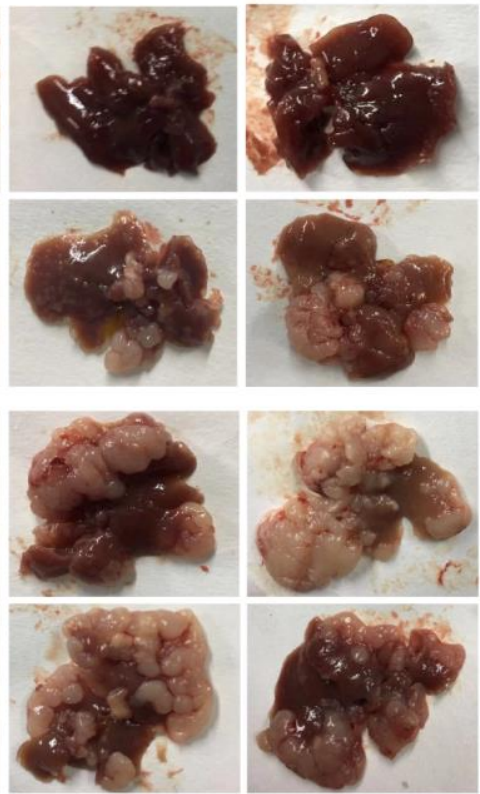

CT26 colon cancer liver metastases

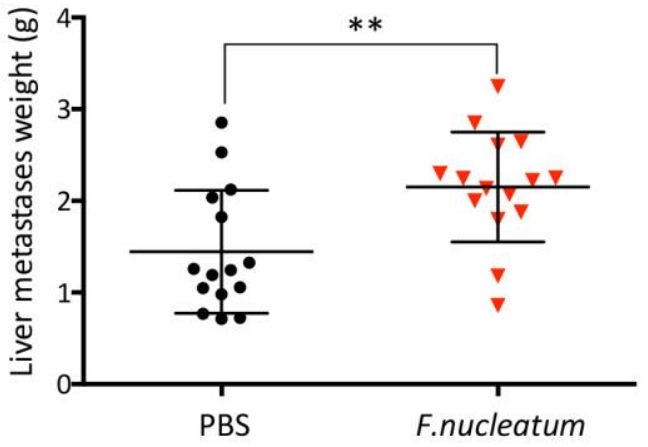

B

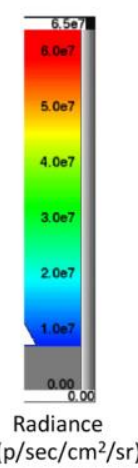

B

Total luciferase signal

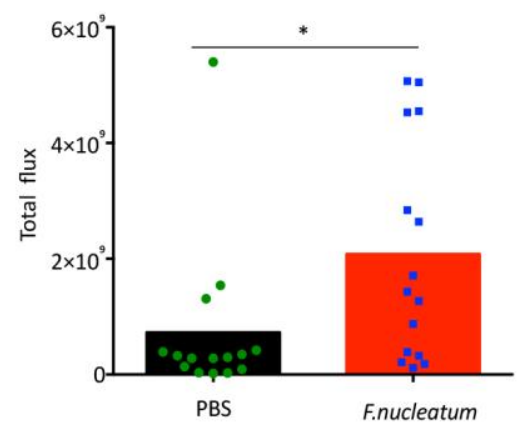

D

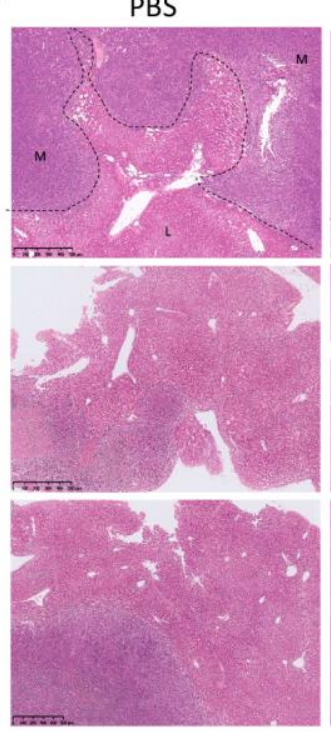

F.nucleatum

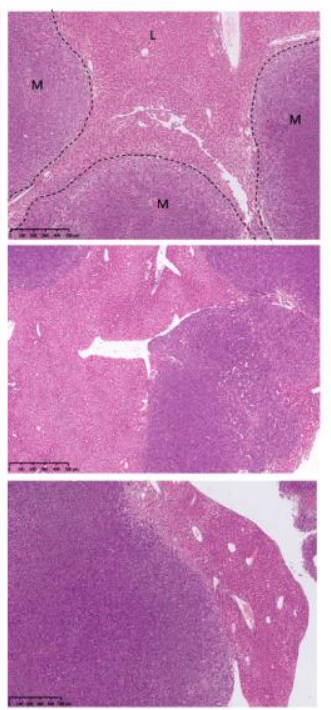

F

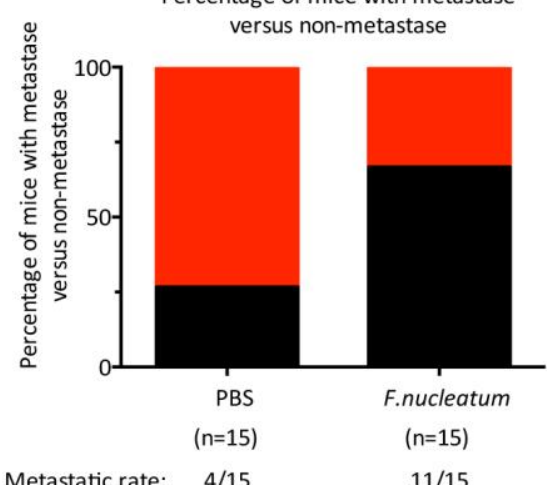

Metastatic rate: $\quad 4 / 15$

Non-metastases

Figure 2. Administration of Fusobacterium nucleatum promotes liver metastasis of colorectal cancer in mice. (A, B) PBSresuspended $10^{9}$ colony-forming units of $F$. nucleatum or PBS were administrated to mice for 8 weeks by gavage every day. The mice received intra-splenic injection post 2-week administration of $F$. nucleatum or PBS intragastrically. At day 28 after intra-splenic transplantation of CT26-Luc cells, in vivo bioluminescence imaging was used to assess liver metastases (A) of BALB/c mice ( $n=15$ per group). (B) The corresponding data expressed by the change in the total signal flux. Data are presented as mean \pm standard deviation (SD; $* P<0.05, * * P<$ 0.01 , and ${ }^{* * *} P<0.001$; unpaired Student's t-test). (C, D) After the 2-week treatment of $F$. nucleatum or PBS, mice received intra-splenic injection of CT26 tumor cells. Four weeks later, the mice were euthanized, and subsequent histological studies were performed. The representative metastatic foci (C) and hematoxylin and eosin-stained liver sections (D) in mice are shown. (E, F) Livers were weighed (E) and liver metastatic rates were measured (F). Data are presented as mean \pm SD $\left({ }^{*} P<0.05, * * P<0.01\right.$, and $* * * P<0.001$; unpaired Student's t-test). 
sequencing. Subsequent analyses of the rarefaction curves illustrated that the species richness in the gut microbiome of the $F$. nucleatum-treated mice was evidently lower than that of PBS-treated mice (Figure 5A). Correspondingly, the abundance curve also showed reduced species richness and lower species uniformity in the gut microbiome of the $F$. nucleatumtreated mice (Figure 5B) as compared to that in the PBS-treated mice. Further evaluation of the microbial diversity using the Shannon Index (Figure 5C) and Chao1 Index (Figure 5D) revealed a significant reduction in species diversity upon $F$. nucleatum gavage as compared to that in control group. Overall, these findings suggest that $F$. nucleatum exerts a significant effect on the abundance and diversity of gut bacteria.

Previous studies have shown that dysbiosis and associated impairment in the gut microenvironment especially manifest in the distal gut, particularly in the cecum [23, 24]. Moreover, cecal weight has been reported to be associated with intestinal microbial abundance and diversity [25]. Consequently, the murine cecum as well as metastatic livers from the $F$. nucleatum or PBS-treated mice with established CRC were dissected post euthanization and weighed. The results revealed that $F$. nucleatum-treated mice demonstrated

C

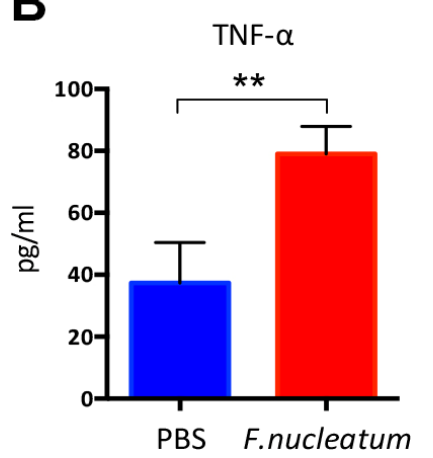

$\mathbf{F}$
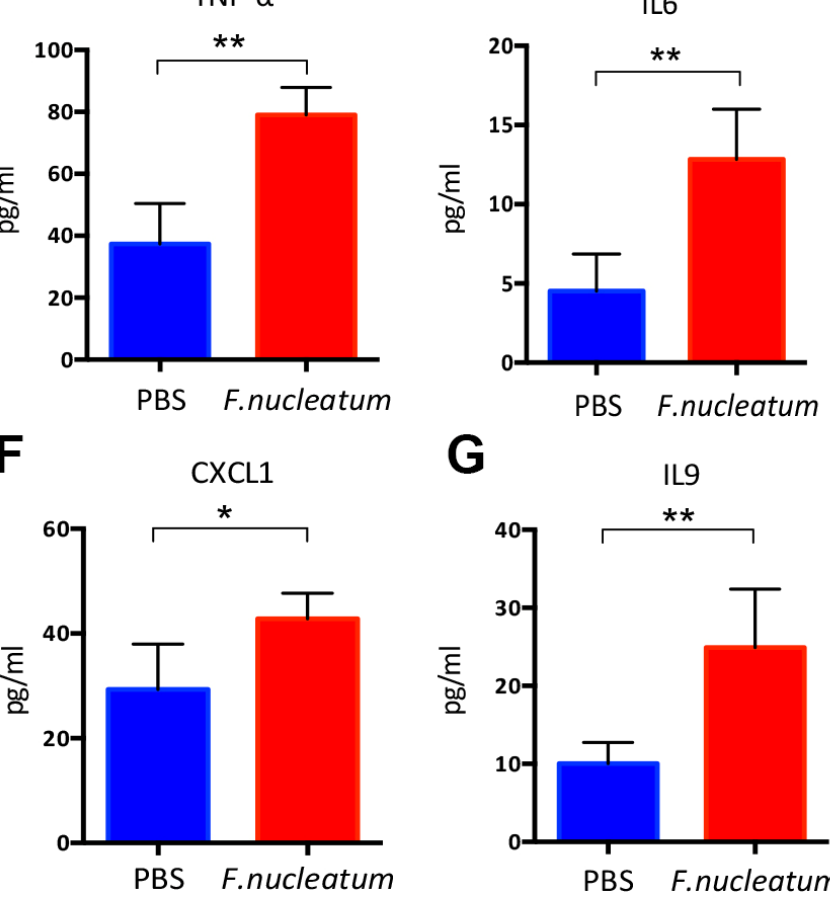

$\mathbf{G}$

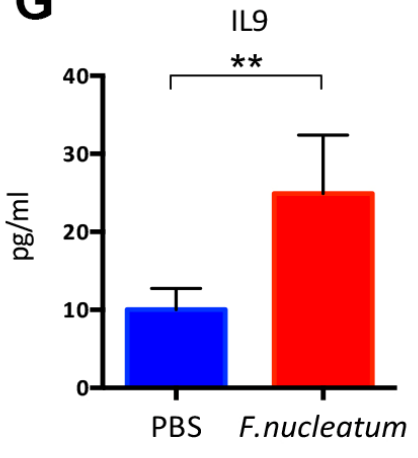

D

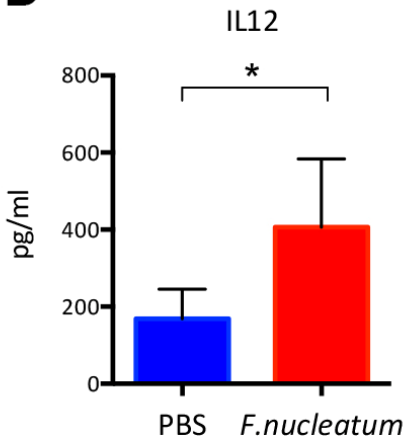

H

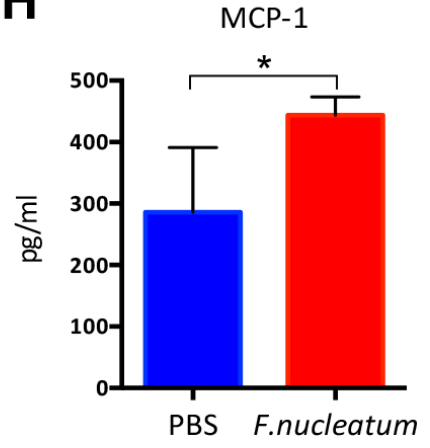

K

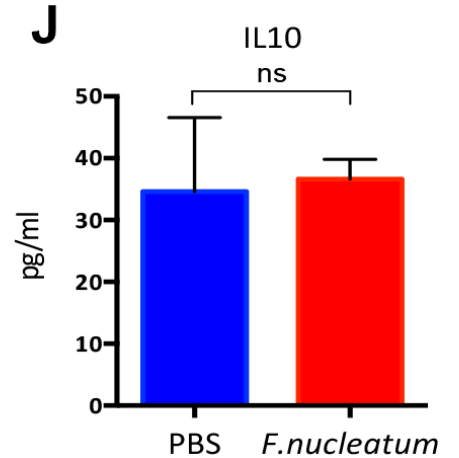

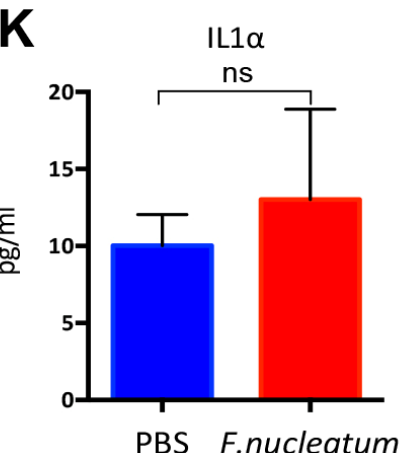

Figure 3. Fusobacterium nucleatum regulates the levels of inflammatory cytokines in mice plasma. (A-K) Concentrations of the pro-inflammatory cytokines, (A) Interferon-gamma (IFN- $\gamma$ ), (B) tumor necrosis factor- $\alpha$ (TNF- $\alpha$ ), (C) IL6, (D) IL12, (E) IL17A, (F) chemokine (C-X-C) motif ligand (CXCL1), (G) IL9, (H) macrophage chemoattractant protein-1(MCP-1), (I) Eotaxin, (J) IL10, (K) IL1 $\alpha$ in murine plasma were detected by the Bio-Plex Pro Mouse Cytokine Array kit. Data are presented as mean \pm standard deviation ( $n=5$ per group). ${ }^{*} P<$ $0.05, * * P<0.01$, and $* * * P<0.001 ;$ unpaired Student's t-test. 

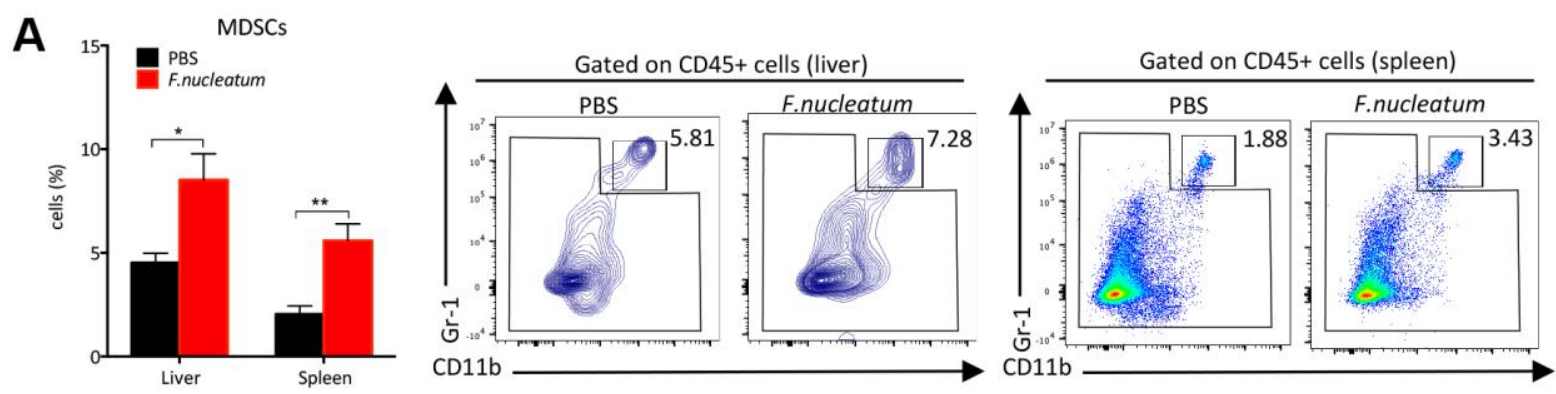

B
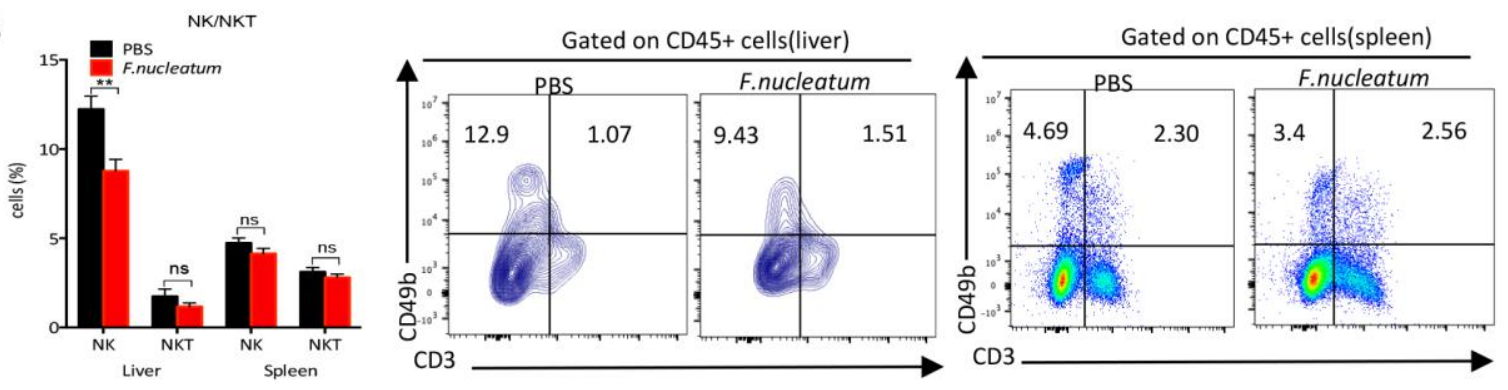

C

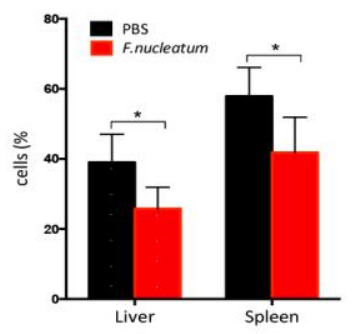

Gated on CD45+ cells (liver)
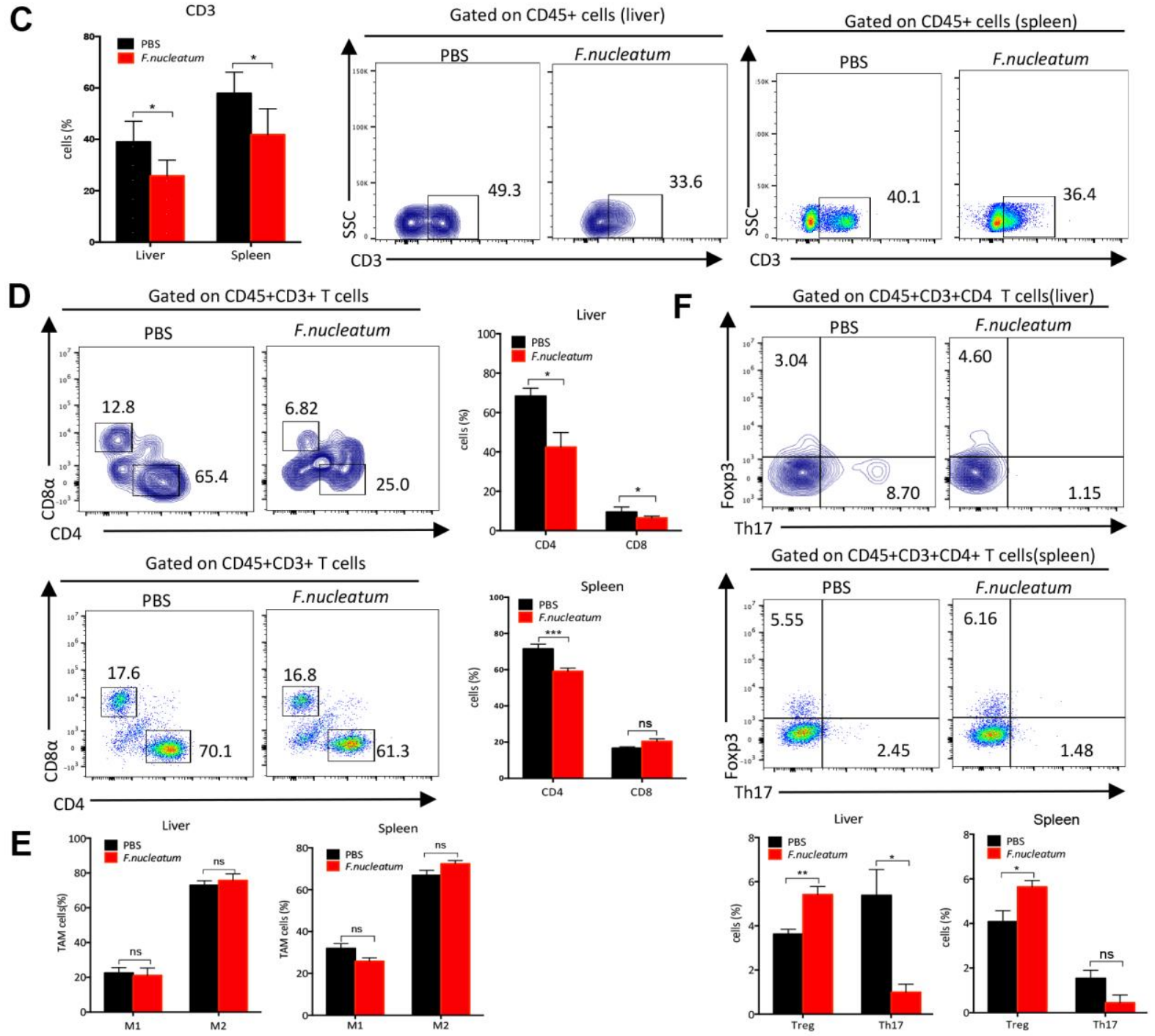

Figure 4. Fusobacterium nucleatum aggravates colorectal cancer liver metastasis by restructuring the liver immune microenvironment. (A) Myeloid-derived suppressor cells (MDSCs; $C D 45^{+} C D 11 b^{+} G r-1^{+}$) in the liver and spleen were determined by flow 


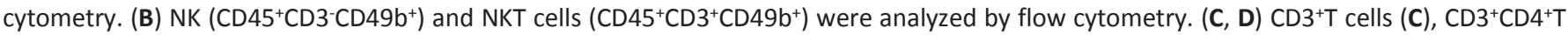
cells and $\mathrm{CD} 3^{+} \mathrm{CD} 8^{+} \mathrm{T}$ cells (D) in the liver and spleen were assessed by flow cytometry and analyzed by gating on lymphocytes and $\mathrm{CD} 3^{+}$cells. (E) Tumor-associated macrophages $\left(C D 45^{+} \mathrm{CD} 11 \mathrm{~b}^{+} \mathrm{F} 4 / 80^{+}\right)$in the liver and spleen were determined by flow cytometry. (F) Treg cells $\left(\mathrm{CD} 4^{+} \mathrm{Foxp}^{+}\right)$and Th17 cells $\left(\mathrm{IL} 17^{+} \mathrm{CD} 4^{+}\right)$were evaluated by flow cytometry and analyzed by gating on CD4 ${ }^{+} \mathrm{T}$ cells. Data are presented as mean \pm standard deviation ( $\mathrm{n}=5$ per group). ${ }^{*} P<0.05,{ }^{*} P<0.01$, and $* * * P<0.001$; unpaired Student's t-test.

A

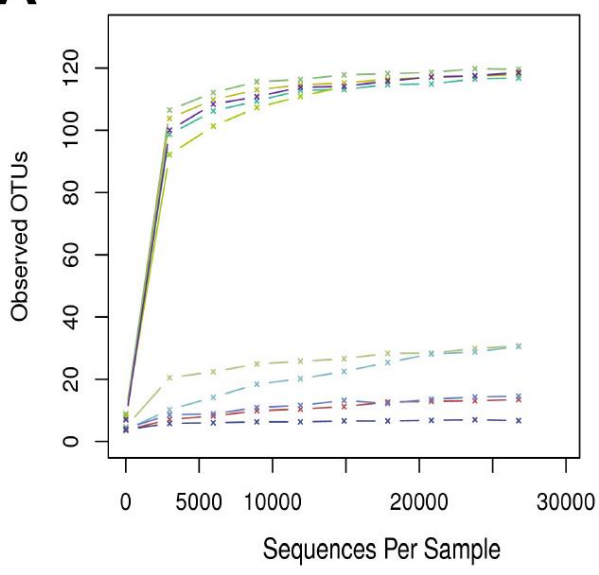

C

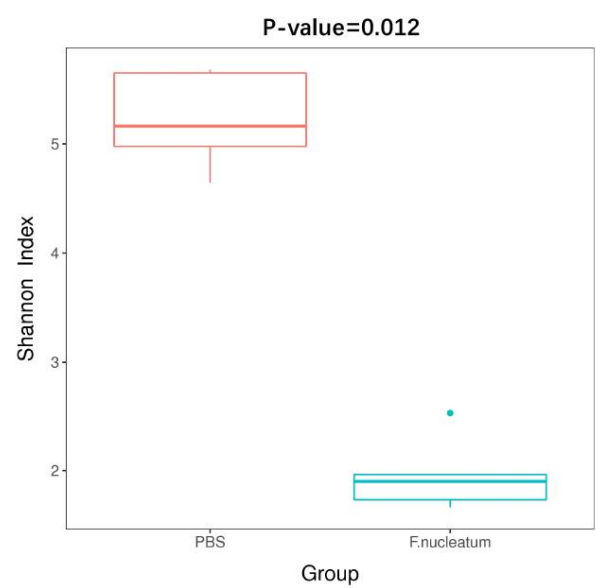

Relative cecum weight

$\mathbf{E}$

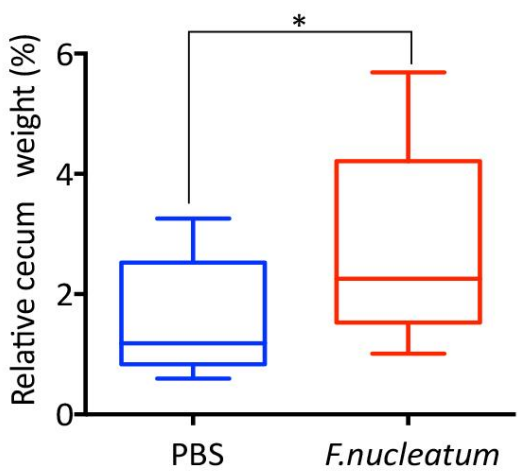

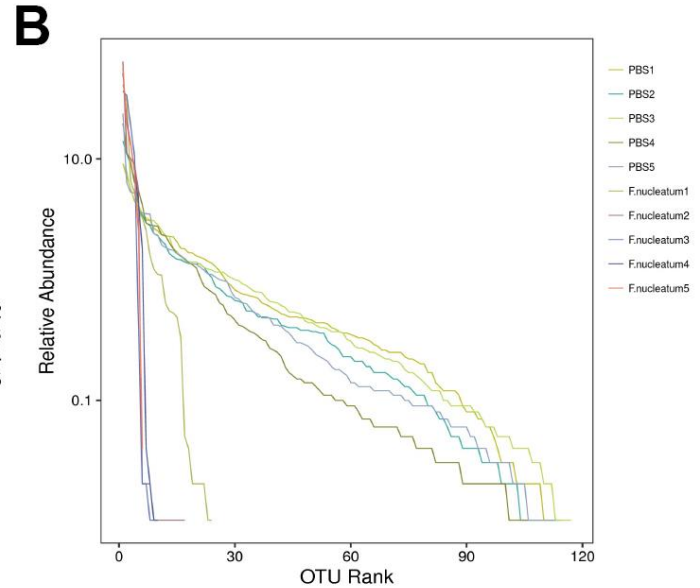

D

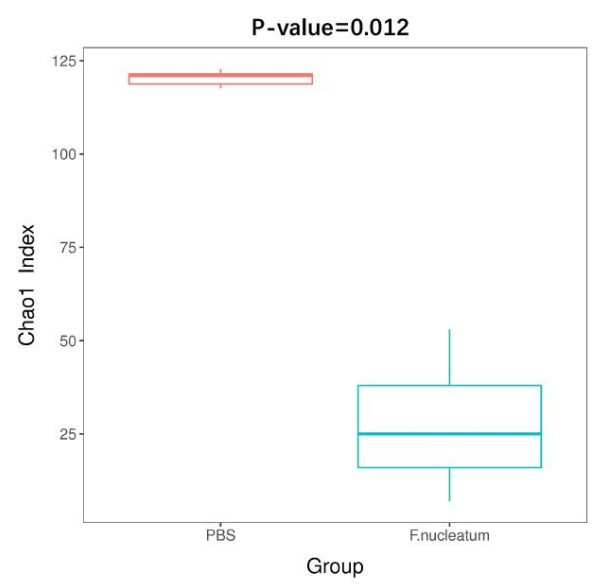

The ratio of liver metastases weight and

$\mathbf{F}$ cecum weight

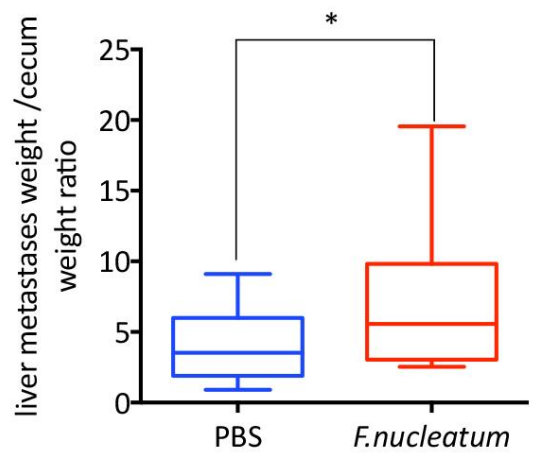

Figure 5. Fusobacterium nucleatum-induced intestinal microbial dysbiosis is involved in the development of colorectal cancer liver metastasis. (A-D) The rarefaction curve (A), relative abundance curve (B), Shannon diversity index (C), and Chao1 diversity index (D) of intestinal bacteria in mice treated with F. nucleatum or PBS were assessed by $16 \mathrm{~S}$ rRNA sequencing ( $\mathrm{n}=5$ per group). Data are presented as mean \pm standard deviation (SD; unpaired Student's t-test). (E, F) The cecum and livers of mice were dissociated and weighed. The relative cecum weight (cecum weight/body weight) $(E)$ and the metastatic liver weight/cecum weight $(\mathrm{MLW} / \mathrm{CW}) \mathrm{ratio}(\mathbf{F})$ were measured. Data are presented as mean $\pm \mathrm{SD}$ ( $\mathrm{n}=15$ per group). ${ }^{*} P<0.05,{ }^{* *} P<0.01$, and ${ }^{* * *} P<0.001$; unpaired Student's t-test. 
a higher relative cecum weight (cecum weight/ body weight) (Figure 5E) and MLW/CW (metastatic liver weight/cecum weight) ratio (Figure 5F) than those noted with PBS-administered mice; which was concomitant with the increased tumor burden.

\section{Gut bacterial composition and community structure is altered post $\boldsymbol{F}$. nucleatum administration}

To determine the alteration in the gut bacterial composition and community structure upon treatment $F$. nucleatum, the fecal microbiota composition and community of mice treated with $F$. nucleatum or PBS were examined. The principal co-ordinate analysis (PCoA) and non-metric multidimensional scaling (NMDS) analysis revealed that the intestinal bacterial flora is substantially altered after $F$. nucleatum exposure as compared to that with PBS treatment (Figure 6A, 6B). The analysis of weighted and unweighted UniFrac distance further indicated that $F$. nucleatum instigated a disturbance in the microbiota, and that the gut bacterial community structure was significantly different between the $F$. nucleatum and PBS-administered groups (Figure 6C, 6D).
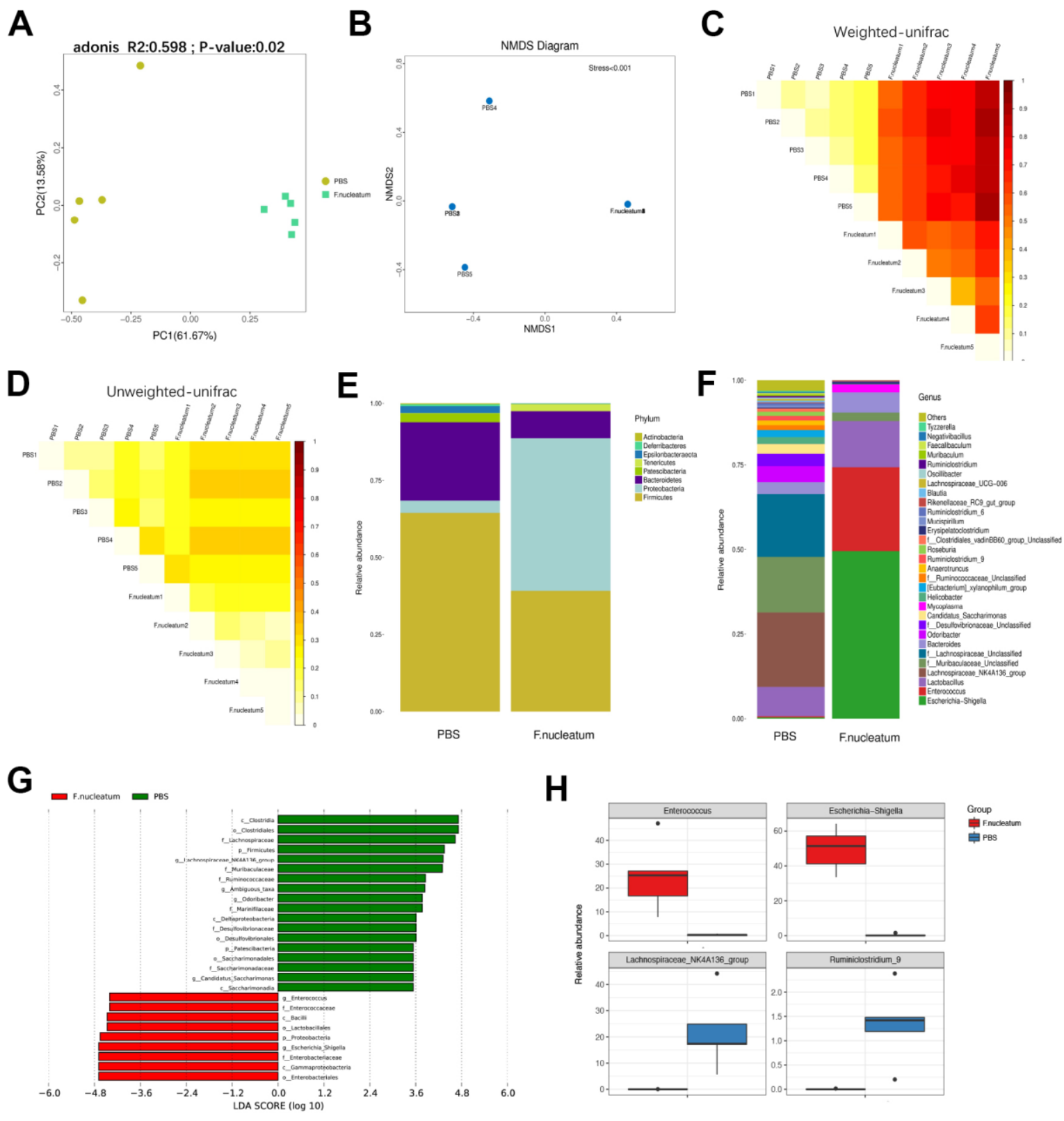

Figure 6. Gut bacterial composition and community structure is altered after Fusobacterium nucleatum administration (A) Principal component analysis was performed on $16 \mathrm{~S}$ rRNA sequencing of stool samples from mice treated with either $F$. nucleatum or PBS ( $\mathrm{n}=5$ per 
group). Significant differences $(P<0.05)$ in intestinal microbiota composition between the two groups were analyzed via PERMANOVA (adonis). (B-D) The beta diversity of intestinal bacteria was compared by non-metric multidimensional scaling analysis (B) and weighted (C) and unweighted (D) UniFrac distance analysis between PBS- and F. nucleatum-treated groups. (E, F) The alteration of intestinal bacterial patterns at the phylum level (E) and genus level (F) in mouse stool from the PBS and $F$. nucleatum groups was assessed via 16S rRNA sequencing ( $n=5$ per group). (G) Specific phylotypes of gut bacteria in the two groups using LEfSe. The histogram shows the LDA scores $>3.5$ at the operational taxonomic unit level. $(\mathbf{H})$ The top four genera with the largest difference between the two groups of mice treated with either F. nucleatum or PBS.

Furthermore, our results revealed that $F$. nucleatum gavage increases the relative abundance of Proteobacteria but decreases the relative abundance of Bacteroidetes at the phylum level (Figure 6E) as compared to PBS administration. The relative abundance of Lachnospiraceae_NK4A136_group was lower, but Bacteroides and Lactobacillus were significantly more abundant in the $F$. nucleatum-treated mice as compared to the PBS-administered mice (Figure 6F). Subsequent analysis using the linear discriminant analysis (LDA) effect size (LEfSe) algorithm indicated that the two groups had completely different taxa (Figure 6G). However, the specific groups with the largest difference between the two groups of mice were determined at the genus level (Figure 6H). Specifically, the $F$. nucleatum-treated mice contained a higher abundance of Enterococcus and Escherichia/Shigella as compared to PBS-treated mice. Moreover, the relative abundances of Lachnospiraceae_NK4A136_group and Ruminiclostridium_9 were lower in $F$. nucleatumtreated as compared to the PBS-treated mice.

\section{DISCUSSION}

Advances in high-throughput sequencing technology have enabled researchers to appreciate the crucial role of gut microbiota in the initiation and progression of CRC [26]. Studies have suggested a strong association of $F$. nucleatum enrichment in gut microbiota with colorectal carcinogenesis $[27,28]$ that potentiates CRC cell proliferation, adhesion, and invasion by activating relevant cancer-signaling pathways $[15,16,29]$ or modulating the immune response [30, 31]. However, the potential role of $F$. nucleatum in CRLM remains poorly understood. In this study, we have elucidated that $F$. nucleatum administration promotes CRLM and is correlated with the activation of hepatic immune microenvironment. Interestingly, a recent study has innovatively demonstrated that $F$. nucleatum can be detected in liver metastases and the $F$. nucleatumpositive CRLM are associated with the reduced density of $\mathrm{T}$ cells [32]. Consistent with these findings, using in vivo murine models of $\mathrm{CRC}$, we have shown that $F$. nucleatum reshapes the immune microenvironment in metastatic livers. Furthermore, our results also evidently revealed the crosstalk between $F$. nucleatum-induced dysbiosis and liver immune environment.
Our results confirmed that $F$. nucleatum modulates the immune response and promotes CRLM by affecting the gut microbiota using in vivo mice models of CRC. In this study, we have demonstrated that $F$. nucleatum administration significantly alters the plasma concentrations of different pro-inflammatory cytokines. Particularly, significant upsurges were observed in IL17A, TNF- $\alpha$, IL6, IL12, Eotaxin, CXCL1, IFN- $\gamma$, MCP-1, and IL9 in the plasma concentrations of mice with established CRC upon administration of $F$. nucleatum as compared to that upon PBS treatment, suggesting an inflammation promoting role of $F$. nucleatum. Consistent with our findings, $F$. nucleatum has been documented to be enriched in inflammatory bowel disease (IBD) and colorectal adenomas [21], whereas in CRC, patients demonstrate higher concentrations of inflammatory cytokines as compared to healthy individuals [33-35].

The elevation in the levels of the pro-inflammatory cytokines such as MCP-1, Eotaxin, IL12, and IL6 is indicative of chronic inflammation. Several studies have proven the association of pro-inflammatory cytokines in the TME with tumor progression due to their ability to recruit $\mathrm{CD}^{+} \mathrm{T}$ cells, stimulate TAM polarization, accumulate Treg cells, and facilitate angiogenesis [36-40]. Accordingly, our results further corroborated that high levels of these cytokines are associated with CRC metastasis [41].

IFN- $\gamma$ and IL9 play important roles in anti-tumor activity [42, 43]. However, IFN- $\gamma$ can promote CRC proliferation and metastasis by inducing a proinflammatory effect [44], which is in agreement with our findings. In addition, IL9 expression in CRC samples has been reported to be significantly higher than that in the surrounding healthy mucosa, suggesting its tumorigenic role in CRC [45].

IL17A and TNF- $\alpha$ are important inflammatory cytokines linked to host immunity for CRC initiation, promotion, angiogenesis, and metastasis. IL17A promotes tumor progression by suppressing anti-tumor immune activity, including its impact on $\mathrm{CD} 8^{+} \mathrm{T}$ cell polarization to lose their cytotoxic ability $[46,47]$. The higher concentrations of IL17A and TNF- $\alpha$ following $F$. nucleatum administration in our findings are therefore consistent with previous findings [48]. 
Our studies further revealed that $F$. nucleatum stimulation increases the number of MDSCs in the spleen and liver of mice with established CRC as compared to PBS-administered mice. The recruitment of MDSCs into the liver has been documented to modulate immunosuppression by inhibiting NK cell cytotoxicity and inducing the accumulation of Tregs [49]. Circulating MDSCs have been reported to correlate with tumor metastasis, clinical stage, and target treatment in CRC. Moreover, CXCL1 is critical for the formation of a pre-metastatic niche for CRC metastasis via the recruitment of MDSCs [50]. Thus, our findings showing higher levels of CXCL1 upon stimulation of mice with CRC by $F$. nucleatum indicate that $F$. nucleatum may be involved in the promotion of $\mathrm{CRC}$ metastasis, which is in agreement with a previous study [39].

NK cells are an abundant class of lymphocytes with an effective cytotoxic response and cytokine production that facilitate elimination of cancer. Primarily, these cells are vital effectors of the innate immune response that protect the host organism against pathogens via non-specific mechanisms [51]. In agreement with previous studies, our study has also shown that $F$. nucleatum treatment abolishes the innate immune response [52]. Furthermore, Gur et al. [19] have reported that the reduction of NK cells upon $F$. nucleatum treatment results in impaired NK cell-mediated cytotoxic activity in CRC tumors.

Further evaluation of peripheral and hepatic $\mathrm{T}$ cell responses in a murine $\mathrm{CRC}$ model administered with. $F$. nucleatum led to a decreased $\mathrm{CD}^{+} \mathrm{T}$ cell and total $\mathrm{T}$ cell subpopulations $\left(\mathrm{CD}^{+}\right.$and $\mathrm{CD}^{+} \mathrm{T}$ cells), inhibiting the adaptive immune responses in the murine liver. Indeed, it has been proven that $\mathrm{T}$ cell-modulated adaptive immune responses play an important role in CRC progression [53]. In this study, $F$. nucleatum exposure resulted in upregulation of Treg cell population in both the spleen and liver, which is further supported by the previous findings from $\mathrm{Ma}$ et al. [13]. A number of studies have demonstrated that Tregs play an important role in suppressing immune responses by modulating MDSCs to drive tolerance, suggesting that Tregs can potentially inhibit anti-tumor immunity in the liver $[54,55]$.

The balance between the Treg and Th17 cells is crucial for the regulation of pro- and anti-tumor immunity [56]. Elevated levels of Th17-related cytokines in advanced CRC are reported to be associated with poor outcomes [57]. In accordance with previous findings, the secretion of Th17-associated cytokines (TNF- $\alpha$, IL6, and IL17A) was found to be significantly augmented in the plasma, concomitant with decreased infiltration of Th17 cells in the livers of mice belonging to the $F$. nucleatum group as compared to the PBS group. Th17 plays a dual role in CRC development [56]. Wang et al. have demonstrated an immunosuppressive effect of Th17 within the TME through inhibition of $\mathrm{CD}^{+} \mathrm{T}$ cell migration to tumors [58]. Nevertheless, previous studies have shown that Th17 cells can recruit effector T cells and NK cells to support anti-tumor immunity [59]. Ling et al. have confirmed that decreased Th17 infiltration is associated with CRC progression in patients [60], which is in agreement with our findings.

The role of the gut microbiota in modulating host immunity has received increasing attention in recent times. It is well-established that immune system influences the composition of the gut microbiota. Studies have demonstrated a critical role of the gut microbiota in the initiation and development of CRC, and that inflammation via IBD can drive the loss of microbiota diversity, leading to a distinct composition of microbial community [24, 61]. Our study has demonstrated that oral administration of $F$. nucleatum remarkably reduced the diversity of the intestinal microbiota and altered its composition as compared to the control group; although the Fusobacteria were not detected in the feces of mice, which may be attributed to the small group size and insufficient administration period. Further evaluation of the gut microbiota composition demonstrated a higher abundance of pathogenic bacteria, such as Proteobacteria, in the $F$. nucleatum group than in the PBS group at the phylum level. At the genus level, increased Enterococcus and Escherichia/Shigella abundance were detected in mice treated with $F$. nucleatum as compared to those administered with PBS as control. Consistent with our results, a reduction in the abundance of Clostridia and an elevated abundance of Enterococcus and Escherichia/Shigella has been reported in mice demonstrating CRLM [13]. Previous study thus highlights the driver-passenger model, wherein, the driver bacteria Enterococcus or Escherichial Shigella produce genotoxic substances to damage the epithelial cell DNA, whereas $F$. nucleatum as the passenger bacterium favors the proliferation of cancer cells to promote CRC tumorigenesis [62]. In contrast, the administration of $F$. nucleatum was also found to be associated with decreased abundance of Lachnospiraceae_NK4A136_group and Ruminiclostridium_9. A previous study reported that Lachnospiraceae_NK4A136_group is more abundant in healthy individuals than in the CRC patients [63]. Furthermore, an elevated abundance of Ruminiclostridium_9 has been documented post administration of a probiotic [64]. These results imply that Lachnospiraceae_NK4A136_group and Ruminiclostridium_9 may play a protective role in CRC progression. 
Despite significant studies, whether the alteration of gut microbiota is a reason or a consequence of liver metastasis of CRC is still unclear. Due to the gut-liver axis, the liver receives toxins and microorganisms via the portal vein from the gut to ensure that it can metabolize gut-derived microbial products and nutrients. Moreover, it has been documented that metastatic liver demonstrates altered hepatic cyto-architecture, ensuing a pro-inflammatory state and metabolic disorders $[65,66]$. Accumulation of the harmful metabolic products damages the composition of healthy intestinal flora, altering the composition of gut microbiota. Moreover, the commensal bacteria are important regulators of antitumor immunity. It has been reported that alterations in the gut microbiota can exacerbate the liver metastases through the production of prostaglandins to suppress tumor immunity [67], increasing the intestinal permeability to induce the hepatic inflammation [68], and altering the bile acid composition [69]. In the present study, the administration of $F$. nucleatum was found to result in dysbiosis and modulated the hepatic immune environment to promote the liver metastases. Previous studies have shown that disequilibrium of intestinal microflora can regulate the liver immune environment through several mechanisms, including the activation of intestinal inflammation, and accumulation of bacterial as well as metabolic products [14, 70-72]. Certain metabolites secreted from Enterococcus faecalis or FadA in F. nucleatum have been reported to damage DNA, resulting in enhanced proliferation of colon cancer cells in studies on gut microbiota in cancer patients [73]. Clostridium and its metabolites have been shown to promote $\mathrm{T}$ cell accumulation and differentiation to alleviate colitis in mice [74]. Enterococcus and Escherichia/Shigella have been found to change gut permeability and promote inflammation in the liver because of the high level of lipopolysaccharides (LPS) [75]. Thus, F. nucleatum may partially promote CRLM through modulation of the liver immune microenvironment as a result of an imbalanced intestinal microflora. However, the exact mechanisms mandate further investigation to delineate the detailed molecular mechanism underlying the regulation of the liver immune response by the $F$. nucleatum-induced dysbiosis.

In conclusion, our study demonstrated that administration of $F$. nucleatum affects the secretion of inflammatory cytokines and modulates the hepatic immune response to promote CRLM. These changes are attributed to alterations in the structure and composition of the gut microbiota. However, these findings need to be validated with additional studies. Nonetheless, our findings provide new insights for the development of innovative therapeutic strategies for targeting microbiota in patients with CRLM.

\section{MATERIALS AND METHODS}

\section{Bacterial culture}

The F. nucleatum strain ATCC 25586 was purchased from the China General Microbiological Culture Collection Center (CGMCC, Beijing, China). The bacteria were grown in brain heart infusion (Beijing Land Bridge Technology, Beijing, China) broth medium supplemented with $5 \mathrm{mg} / \mathrm{L}$ heme (Beijing Land Bridge Technology) and $1 \mathrm{mg} / \mathrm{L}$ vitamin K1 (Beijing Land Bridge Technology) under anaerobic conditions (AnaeroPack; Mitsubishi Gas Chemical, Tokyo, Japan) at $37^{\circ} \mathrm{C}$ for $48 \mathrm{~h}$ before harvesting.

\section{Cell culture}

The CT26 mouse colon carcinoma cell line was obtained from the Cell Bank of the Chinese Academy of Sciences (Shanghai, China) and stably transfected with the luciferase gene, to generate CT26-Luciferase (CT26-Luc) cell line. CT26-Luc colon cells were cultured in RPMI 1640 (HyClone, GE Healthcare; Chicago, IL, USA) supplemented with $10 \%$ fetal bovine serum (FBS; Gibco, Thermo Fisher Scientific Corp., Waltham, MA, USA) at $37^{\circ} \mathrm{C}$ in a humidified 5 $\% \mathrm{CO}_{2}$ atmosphere.

\section{Mice}

Six to eight-week-old male BALB/c mice were purchased from the Experimental Animal Center of Hubei Province, China. All mice were raised under specific-pathogen-free barrier conditions and fed autoclaved food and water according to the institutional guidelines for Animal Care and Use Committee of Tongji Hospital, Huazhong University of Science and Technology, Hubei, China. The body weight of the mice was measured twice a week. All animal protocols were approved by the Ethical Committee on Animal Experiments.

Before intragastric administration of bacteria, streptomycin $(2 \mathrm{mg} / \mathrm{mL}$, Shanghai Macklin Biochemical Co., Ltd Shanghai, China) was administered to all mice used in the study via drinking water for three days. To investigate $F$. nucleatum-associated CRLM, 30 mice were randomly assigned to two groups and $10^{9}$ colonyforming units of $F$. nucleatum resuspended in PBS were administered to mice by gavage every day for eight weeks. After the 4-week F. nucleatum or PBS administration, the CT26-Luc cells were injected into the spleens of $\mathrm{BALB} / \mathrm{c}$ mice to establish a liver metastasis model, which were denoted as $F$. nucleatum group and PBS group, respectively. Another 30 mice were administered with $F$. nucleatum or PBS 
until moribund to investigate $F$. nucleatum-associated survival.

\section{Flow cytometry}

Livers and spleens were collected from mice post completion of the in vivo experiments. The tissues were minced and dissociated in cell culture medium containing $0.01 \%$ type IV collagenase and $0.001 \%$ DNase I for $45 \mathrm{~min}$ at $37^{\circ} \mathrm{C}$. The mixture was subsequently filtered carefully through a $70-\mu \mathrm{m}$ nylon cell strainer to obtain a single-cell suspension. The suspension was subsequently purified by gradient centrifugation with 30-70 \% Percoll [76]. According to the manufacture's recommendation, cell surface markers were stained with the indicated antibodies for $30 \mathrm{~min}$ at $4^{\circ} \mathrm{C}$ and live cells were surface-labeled by Fixable Viability Stain 780 (BD Biosciences, San Jose, CA, USA). Cells were then permeabilized in transcription factor buffer (BD Biosciences) and subjected to intracellular Foxp3 staining using relevant monoclonal antibodies. For intracellular IL17 staining, cells were stimulated in complete medium (RPMI 1640 containing $10 \%$ FBS, $1 \%$ penicillin and streptomycin) for $12 \mathrm{~h}$ in the presence of Leukocyte Activation Cocktail with GolgiPlug ( $2 \mu \mathrm{L} / \mathrm{mL}$, BD Biosciences) and then stained with the indicated antibodies. The following antibodies were used for flow cytometry analysis: anti-CD8 $\alpha$-FITC (53-6.7, BD Biosciences), anti-IL17A-PE (TC11-18H10, BD Biosciences), antiCD3-BB700 (145-2C11, BD Biosciences), anti-Foxp3 Alexa Fluor 647 (MF23, BD Biosciences), anti-CD4BV421 (GK1.5, BD Biosciences), anti-CD45-BV480 (30-F11, BD Biosciences), anti-CD49b-PE (DX5, BD Biosciences), anti-CD206 Alexa Fluor 647 (MR5D3, BD Biosciences), anti-F4/80 BV421 (T45-2342, BD Biosciences), anti-CD11b-FITC (M1/70, BD Biosciences), and anti-Ly-6G/Ly-6C-PE-CF594 (RB68C5, BD Biosciences). Stained cells were collected using a CytoFLEX LX Flow Cytometer (Beckman Coulter, Carlsbad, CA, USA) and analyzed using FlowJo (FlowJo LLC, Ashland, OR, USA).

\section{Detection of plasma cytokines}

Plasma cytokines were detected by Luminex suspension chip detection technology provided by Wayen Biotechnologies Inc., Shanghai, China. Following the manufacturer's instructions, the BioPlex Pro Mouse Cytokine Array kit was used for detection of cytokines. Diluted mouse plasma was incubated in a 96-well plate embedded with microbeads for $30 \mathrm{~min}$ at room temperature under dark conditions. The samples were then incubated with the detection antibody for $30 \mathrm{~min}$. Subsequently, streptavidin-PE was added to each well for the development of color rendering, and the calibrated Luminex 200 machine was used to measure its value.

\section{Establishment of liver metastasis model and its imaging}

The liver metastasis model was generated by intrasplenic injection of $1 \times 10^{6}$ CT26-Luc cells via an insulin syringe, and the compression of blood after 3 min of hemostasis. After four weeks, fluorescent images were captured using in vivo luciferase imaging system to observe the metastatic foci in the liver. All mice were anesthetized with $1.5 \%$ pentobarbital sodium and euthanized for tumor statistics and histopathologic analysis. The livers and cecum were also dissected, weighed, and photographed.

The development of metastases was monitored by IVIS (Lago, Spectral Instruments Imaging; Tucson, AZ, USA). All mice were anesthetized with $1.5 \%$ pentobarbital sodium and injected intraperitoneally with D-luciferin at a dose of $1.5 \mathrm{mg}$ per $10 \mathrm{~g}$ body weight, and 15 min later, luciferase imaging was performed. The images were analyzed using Living Image software (PerkinElmer, Waltham, MA, USA). An equal size of the abdominal region was assigned as the ROI, and the number of photons emitted per second (photon/s) in the ROI was acquired for quantitative analysis.

\section{High-throughput sequencing}

Stool samples from the distal rectum were immediately collected and stored in liquid nitrogen after euthanizing the mice. The concentration of DNA extracted from the stool was detected using a Qubit 2.0 Fluorometer (Invitrogen, Thermo Fisher Scientific Corp., Waltham, MA, USA). High-throughput sequencing and construction of the sequencing library were performed using Illumina MiSeq (Illumina, San Diego, CA, USA) platform as per the manufacturer's instructions. Operational taxonomic unit analysis clustered sequences at $97 \%$ similarity level using VSEARCH (version 1.9.6) [77]. The rRNA gene database Silva132 was selected for species annotation and taxonomic analysis based on the Ribosomal Database Program (RDP) classifier algorithm [78]. Alpha diversity was evaluated using the Shannon and Chao1 index (http://www.mothur.org/wiki). Beta diversity analysis was performed using the BrayCurtis algorithm and (un)weighted UniFrac. PCoA and NMDS analysis were performed, and rankabundance and rarefaction curves were plotted using QIIME (version 1.9.1) and R software [79]. The LEfSe was analyzed using online tools (http://huttenhower.sph.harvard.edu/galaxy/root?tool_i d=lefse_upload), with an LDA score of 3.5 as the cut- 
off threshold for significant differences. The data were submitted to the Sequence Read Archive database (PRJNA676655).

\section{Hematoxylin and eosin (H\&E) staining}

The liver tissue with or without metastasis in each group was fixed in $4 \%$ paraformaldehyde (Wuhan Servicebio Technology Co., Ltd., Hubei, China) and embedded in paraffin. Paraffin sections $(5 \mu \mathrm{m})$ were then stained with H\&E (Biossci, Hubei, China) to determine hepatic metastases.

\section{Statistical analysis}

Data are presented as the mean \pm standard deviation or the mean \pm standard error of the mean and analyzed using GraphPad Prism 6.0 (GraphPad Software, CA, USA). Survival analysis was assessed using the KaplanMeier method, and the log-rank test was used to compare the difference in survival of the two groups. Student's t-test, the Mann-Whitney U test, and one-way analysis of variance were used for statistical analysis of the data. Differences were considered statistically significant at $P<0.05$.

\section{Abbreviations}

CRC: Colorectal cancer; CRLM: Colorectal cancer liver metastasis; MDSC: Myeloid-derived suppressor cells; NK: Natural killer ; TNF $\alpha$ : Tumor necrosis factor alpha; IFN- $\gamma$ : Interferon-gamma; MCP-1: Macrophage chemoattractant protein-1; CXCL1: chemokine (C-X-C motif) ligand 1; TAM: Tumor-associated macrophage; CGMCC: The China General Microbiological Culture Collection Center; ROI: Region of interest; RDP: Ribosomal Database Program; PCoA: Principal Coordinate Analysis; NMDS: Non-metric Multidimensional Scaling; LDA: Linear Discriminant Analysis; LEfSe: Linear Discriminant Analysis Effect Size; LPS: Lipopolysaccharides.

\section{AUTHOR CONTRIBUTIONS}

Study concept and design: HY and ZM. Animal experiments: HY, ZM, CL, BW, YJ. Data analysis and statistical analysis: LW, BS, HH. Drafting of the manuscript: HY, ZM, XY. All authors have reviewed and agreed with the information provided in the manuscript.

\section{ACKNOWLEDGMENTS}

The authors would like to thank the China General Microbiological Culture Collection for providing the bacterial strain of Fusobacterium nucleatum (ATCC 25586).

\section{CONFLICTS OF INTEREST}

The authors declare that the research was conducted in the absence of any commercial or financial relationships that could be construed as conflict of interest.

\section{FUNDING}

This work was supported by grants from the National Natural Science Foundation of China (2018, 81773360).

\section{REFERENCES}

1. Siegel RL, Miller KD, Jemal A. Cancer statistics, 2019. CA Cancer J Clin. 2019; 69:7-34. https://doi.org/10.3322/caac.21551 PMID:30620402

2. Siegel RL, Miller KD, Fedewa SA, Ahnen DJ, Meester RG, Barzi A, Jemal A. Colorectal cancer statistics, 2017. CA Cancer J Clin. 2017; 67:177-93. https://doi.org/10.3322/caac.21395 PMID:28248415

3. Manfredi S, Lepage C, Hatem C, Coatmeur O, Faivre J, Bouvier AM. Epidemiology and management of liver metastases from colorectal cancer. Ann Surg. 2006; 244:254-9. https://doi.org/10.1097/01.sla.0000217629.94941.cf PMID:16858188

4. Petrelli NJ. Perioperative or adjuvant therapy for resectable colorectal hepatic metastases. J Clin Oncol. 2008; 26:4862-3. https://doi.org/10.1200/JCO.2008.18.5868 PMID:18794535

5. Chen DL, Lu YX, Zhang JX, Wei XL, Wang F, Zeng ZL, Pan ZZ, Yuan YF, Wang FH, Pelicano H, Chiao PJ, Huang P, Xie $\mathrm{D}$, et al. Long non-coding RNA UICLM promotes colorectal cancer liver metastasis by acting as a ceRNA for microRNA-215 to regulate ZEB2 expression. Theranostics. 2017; 7:4836-49. https://doi.org/10.7150/thno.20942 PMID:29187907

6. Ling $H$, Pickard K, Ivan C, Isella C, Ikuo M, Mitter R, Spizzo R, Bullock M, Braicu C, Pileczki V, Vincent K, Pichler $M$, Stiegelbauer $V$, et al. The clinical and biological significance of MIR-224 expression in colorectal cancer metastasis. Gut. 2016; 65:977-89. https://doi.org/10.1136/gutjinl-2015-309372 PMID:25804630

7. Garrett WS. The gut microbiota and colon cancer. Science. 2019; 364:1133-5. https://doi.org/10.1126/science.aaw2367 PMID:31221845

8. Lucas C, Barnich N, Nguyen HT. Microbiota, Inflammation and Colorectal Cancer. Int J Mol Sci. 2017; 18:1310. 
https://doi.org/10.3390/ijms18061310

PMID:28632155

9. Ullman TA, Itzkowitz SH. Intestinal inflammation and cancer. Gastroenterology. 2011; 140:1807-16.

https://doi.org/10.1053/i.gastro.2011.01.057 PMID:21530747

10. Arthur JC, Perez-Chanona E, Mühlbauer M, Tomkovich $\mathrm{S}$, Uronis JM, Fan TJ, Campbell BJ, Abujamel T, Dogan $B$, Rogers AB, Rhodes JM, Stintzi A, Simpson KW, et al. Intestinal inflammation targets cancer-inducing activity of the microbiota. Science. 2012; 338:120-3. https://doi.org/10.1126/science.1224820 PMID:22903521

11. Dapito DH, Mencin A, Gwak GY, Pradere JP, Jang MK, Mederacke I, Caviglia JM, Khiabanian H, Adeyemi A, Bataller R, Lefkowitch JH, Bower M, Friedman R, et al. Promotion of hepatocellular carcinoma by the intestinal microbiota and TLR4. Cancer Cell. 2012; 21:504-16.

https://doi.org/10.1016/i.ccr.2012.02.007 PMID:22516259

12. Sethi V, Kurtom S, Tarique M, Lavania S, Malchiodi Z, Hellmund L, Zhang L, Sharma U, Giri B, Garg B, Ferrantella A, Vickers SM, Banerjee $S$, et al. Gut Microbiota Promotes Tumor Growth in Mice by Modulating Immune Response. Gastroenterology. 2018; 155:33-7.e6. https://doi.org/10.1053/i.gastro.2018.04.001 PMID:29630898

13. Ma $X$, Zhou $Z$, Zhang $X$, Fan $M$, Hong $Y$, Feng $Y$, Dong $\mathrm{Q}$, Diao $\mathrm{H}$, Wang $\mathrm{G}$. Sodium butyrate modulates gut microbiota and immune response in colorectal cancer liver metastatic mice. Cell Biol Toxicol. 2020; 36:509-15.

https://doi.org/10.1007/s10565-020-09518-4 PMID:32172331

14. Ma C, Han M, Heinrich B, Fu Q, Zhang $Q$, Sandhu M, Agdashian D, Terabe M, Berzofsky JA, Fako V, Ritz T, Longerich $\mathrm{T}$, Theriot $\mathrm{CM}$, et al. Gut microbiomemediated bile acid metabolism regulates liver cancer via NKT cells. Science. 2018; 360:eaan5931.

https://doi.org/10.1126/science.aan5931 PMID:29798856

15. Yang $Y$, Weng $W$, Peng J, Hong L, Yang L, Toiyama $Y$, Gao R, Liu M, Yin M, Pan C, Li H, Guo B, Zhu Q, et al. Fusobacterium nucleatum Increases Proliferation of Colorectal Cancer Cells and Tumor Development in Mice by Activating Toll-Like Receptor 4 Signaling to Nuclear Factor-KB, and Up-regulating Expression of MicroRNA-21. Gastroenterology. 2017; 152:851-66.e24.

https://doi.org/10.1053/i.gastro.2016.11.018 PMID:27876571
16. Rubinstein MR, Wang X, Liu W, Hao Y, Cai G, Han YW. Fusobacterium nucleatum promotes colorectal carcinogenesis by modulating $\mathrm{E}$-cadherin/ $\beta$-catenin signaling via its FadA adhesin. Cell Host Microbe. 2013; 14:195-206.

https://doi.org/10.1016/i.chom.2013.07.012 PMID:23954158

17. Gevers $D$, Kugathasan $S$, Denson LA, Vázquez-Baeza $Y$, Van Treuren W, Ren B, Schwager E, Knights D, Song SJ, Yassour M, Morgan XC, Kostic AD, Luo $C$, et al. The treatment-naive microbiome in new-onset Crohn's disease. Cell Host Microbe. 2014; 15:382-92. https://doi.org/10.1016/j.chom.2014.02.005 PMID:24629344

18. Minot S, Sinha R, Chen J, Li H, Keilbaugh SA, Wu GD, Lewis JD, Bushman FD. The human gut virome: interindividual variation and dynamic response to diet. Genome Res. 2011; 21:1616-25. https://doi.org/10.1101/gr.122705.111 PMID:21880779

19. Gur C, Ibrahim Y, Isaacson B, Yamin R, Abed J, Gamliel $\mathrm{M}$, Enk J, Bar-On Y, Stanietsky-Kaynan N, CoppenhagenGlazer S, Shussman N, Almogy G, Cuapio A, et al. Binding of the Fap2 protein of Fusobacterium nucleatum to human inhibitory receptor TIGIT protects tumors from immune cell attack. Immunity. 2015; 42:344-55.

https://doi.org/10.1016/j.immuni.2015.01.010 PMID:25680274

20. Bullman $S$, Pedamallu CS, Sicinska E, Clancy TE, Zhang X, Cai D, Neuberg D, Huang K, Guevara F, Nelson T, Chipashvili O, Hagan T, Walker $M$, et al. Analysis of Fusobacterium persistence and antibiotic response in colorectal cancer. Science. 2017; 358:1443-8.

https://doi.org/10.1126/science.aal5240 PMID:29170280

21. McCoy AN, Araújo-Pérez F, Azcárate-Peril A, Yeh JJ, Sandler RS, Keku TO. Fusobacterium is associated with colorectal adenomas. PLoS One. 2013; 8:e53653. https://doi.org/10.1371/journal.pone.0053653 PMID:23335968

22. Zhang $L, Y u X$, Zheng $L$, Zhang $Y, L i ~ Y$, Fang $Q$, Gao R, Kang B, Zhang $Q$, Huang JY, Konno H, Guo X, $Y e Y$, et al. Lineage tracking reveals dynamic relationships of $T$ cells in colorectal cancer. Nature. 2018; 564:268-72.

https://doi.org/10.1038/s41586-018-0694-x PMID:30479382

23. Kostic AD, Xavier RJ, Gevers D. The microbiome in inflammatory bowel disease: current status and the future ahead. Gastroenterology. 2014; 146:1489-99. https://doi.org/10.1053/i.gastro.2014.02.009 PMID:24560869 
24. Schulz MD, Atay $C$, Heringer J, Romrig FK, Schwitalla S, Aydin B, Ziegler PK, Varga J, Reindl W, Pommerenke C, Salinas-Riester G, Böck A, Alpert C, et al. High-fat-dietmediated dysbiosis promotes intestinal carcinogenesis independently of obesity. Nature. 2014; 514:508-12. https://doi.org/10.1038/nature13398 PMID:25174708

25. Jang YJ, Kim WK, Han DH, Lee K, Ko G. Lactobacillus fermentum species ameliorate dextran sulfate sodium-induced colitis by regulating the immune response and altering gut microbiota. Gut Microbes. 2019; 10:696-711.

https://doi.org/10.1080/19490976.2019.1589281 PMID:30939976

26. Feng $Q$, Liang $S$, Jia $H$, Stadlmayr $A$, Tang $L$, Lan $Z$, Zhang D, Xia H, Xu X, Jie Z, Su L, Li X, Li X, et al. Gut microbiome development along the colorectal adenoma-carcinoma sequence. Nat Commun. 2015; 6:6528.

https://doi.org/10.1038/ncomms7528 PMID:25758642

27. Kostic AD, Gevers D, Pedamallu CS, Michaud M, Duke F, Earl AM, Ojesina Al, Jung J, Bass AJ, Tabernero J, Baselga J, Liu C, Shivdasani RA, et al. Genomic analysis identifies association of Fusobacterium with colorectal carcinoma. Genome Res. 2012; 22:292-8.

https://doi.org/10.1101/gr.126573.111

PMID:22009990

28. Castellarin $\mathrm{M}$, Warren $\mathrm{RL}$, Freeman JD, Dreolini $\mathrm{L}$, Krzywinski M, Strauss J, Barnes R, Watson P, AllenVercoe E, Moore RA, Holt RA. Fusobacterium nucleatum infection is prevalent in human colorectal carcinoma. Genome Res. 2012; 22:299-306.

https://doi.org/10.1101/gr.126516.111

PMID:22009989

29. Abed J, Emgård JE, Zamir G, Faroja M, Almogy G, Grenov A, Sol A, Naor R, Pikarsky E, Atlan KA, Mellul A, Chaushu S, Manson AL, et al. Fap2 Mediates Fusobacterium nucleatum Colorectal Adenocarcinoma Enrichment by Binding to Tumor-Expressed GalGalNAc. Cell Host Microbe. 2016; 20:215-25.

https://doi.org/10.1016/i.chom.2016.07.006 PMID:27512904

30. Kostic $A D$, Chun $E$, Robertson L, Glickman JN, Gallini CA, Michaud M, Clancy TE, Chung DC, Lochhead P, Hold GL, El-Omar EM, Brenner D, Fuchs $\mathrm{CS}$, et al. Fusobacterium nucleatum potentiates intestinal tumorigenesis and modulates the tumorimmune microenvironment. Cell Host Microbe. 2013; 14:207-15.

https://doi.org/10.1016/i.chom.2013.07.007

PMID:23954159

31. Mima K, Sukawa Y, Nishihara R, Qian ZR, Yamauchi M, Inamura K, Kim SA, Masuda A, Nowak JA, Nosho K, Kostic $A D$, Giannakis $M$, Watanabe $H$, et al.
Fusobacterium nucleatum and T Cells in Colorectal Carcinoma. JAMA Oncol. 2015; 1:653-61. https://doi.org/10.1001/jamaoncol.2015.1377 PMID:26181352

32. Sakamoto $Y$, Mima K, Ishimoto $T$, Ogata $Y$, Imai $K$, Miyamoto $Y$, Akiyama T, Daitoku N, Hiyoshi $Y$, Iwatsuki M, Baba Y, Iwagami S, Yamashita YI, et al. Relationship between Fusobacterium nucleatum and antitumor immunity in colorectal cancer liver metastasis. Cancer Sci. 2021; 112:4470-7. https://doi.org/10.1111/cas.15126 PMID:34464993

33. Sears CL, Garrett WS. Microbes, microbiota, and colon cancer. Cell Host Microbe. 2014; 15:317-28. https://doi.org/10.1016/i.chom.2014.02.007 PMID:24629338

34. Irrazábal T, Belcheva A, Girardin SE, Martin A, Philpott DJ. The multifaceted role of the intestinal microbiota in colon cancer. Mol Cell. 2014; 54:309-20. https://doi.org/10.1016/i.molcel.2014.03.039 PMID:24766895

35. Dharmani P, Strauss J, Ambrose C, Allen-Vercoe E, Chadee $\mathrm{K}$. Fusobacterium nucleatum infection of colonic cells stimulates MUC2 mucin and tumor necrosis factor alpha. Infect Immun. 2011; 79:2597-607. https://doi.org/10.1128/IAI.05118-11 PMID:21536792

36. Wang D, Dubois RN, Richmond A. The role of chemokines in intestinal inflammation and cancer. Curr Opin Pharmacol. 2009; 9:688-96.

https://doi.org/10.1016/j.coph.2009.08.003 PMID:19734090

37. Saito $T$, Nishikawa $H$, Wada $H$, Nagano $Y$, Sugiyama $D$, Atarashi K, Maeda Y, Hamaguchi M, Ohkura N, Sato E, Nagase $H$, Nishimura J, Yamamoto $H$, et al. Two FOXP3(+)CD4(+) T cell subpopulations distinctly control the prognosis of colorectal cancers. Nat Med. 2016; 22:679-84. https://doi.org/10.1038/nm.4086 PMID:27111280

38. Liu T, Guo Z, Song X, Liu L, Dong W, Wang S, Xu M, Yang C, Wang B, Cao H. High-fat diet-induced dysbiosis mediates MCP-1/CCR2 axis-dependent M2 macrophage polarization and promotes intestinal adenoma-adenocarcinoma sequence. J Cell Mol Med. 2020; 24:2648-62.

https://doi.org/10.1111/jcmm.14984

PMID:31957197

39. Casasanta MA, Yoo CC, Udayasuryan B, Sanders BE, Umaña A, Zhang Y, Peng H, Duncan AJ, Wang Y, Li L, Verbridge SS, Slade DJ. Fusobacterium nucleatum hostcell binding and invasion induces IL-8 and CXCL1 secretion that drives colorectal cancer cell migration. Sci Signal. 2020; 13:eaba9157. 
https://doi.org/10.1126/scisignal.aba9157

PMID:32694172

40. Wågsäter D, Löfgren S, Hugander A, Dienus O, Dimberg J. Analysis of single nucleotide polymorphism in the promoter and protein expression of the chemokine eotaxin-1 in colorectal cancer patients. World J Surg Oncol. 2007; 5:84.

https://doi.org/10.1186/1477-7819-5-84

PMID:17672898

41. Wei C, Yang C, Wang S, Shi D, Zhang C, Lin X, Liu Q, Dou $\mathrm{R}$, Xiong $\mathrm{B}$. Crosstalk between cancer cells and tumor associated macrophages is required for mesenchymal circulating tumor cell-mediated colorectal cancer metastasis. Mol Cancer. 2019; 18:64.

https://doi.org/10.1186/s12943-019-0976-4

PMID:30927925

42. Purwar R, Schlapbach C, Xiao S, Kang HS, Elyaman W, Jiang $X$, Jetten AM, Khoury SJ, Fuhlbrigge RC, Kuchroo VK, Clark RA, Kupper TS. Robust tumor immunity to melanoma mediated by interleukin-9-producing T cells. Nat Med. 2012; 18:1248-53.

https://doi.org/10.1038/nm.2856 PMID:22772464

43. Mager LF, Wasmer MH, Rau TT, Krebs P. CytokineInduced Modulation of Colorectal Cancer. Front Oncol. 2016; 6:96.

https://doi.org/10.3389/fonc. 2016.00096 PMID:27148488

44. Kobelt D, Zhang C, Clayton-Lucey IA, Glauben R, Voss C, Siegmund B, Stein U. Pro-inflammatory TNF- $\alpha$ and IFNv Promote Tumor Growth and Metastasis via Induction of MACC1. Front Immunol. 2020; 11:980.

https://doi.org/10.3389/fimmu.2020.00980 PMID: $\underline{32670264}$

45. Niccolai E, Russo E, Baldi S, Ricci F, Nannini G, Pedone $M$, Stingo FC, Taddei A, Ringressi MN, Bechi $P$, Mengoni A, Fani R, Bacci G, et al. Significant and Conflicting Correlation of IL-9 With Prevotella and Bacteroides in Human Colorectal Cancer. Front Immunol. 2021; 11:573158

https://doi.org/10.3389/fimmu.2020.573158

PMID:33488574

46. Wu D, Wu P, Huang $Q$, Liu Y, Ye J, Huang J. Interleukin17: a promoter in colorectal cancer progression. Clin Dev Immunol. 2013; 2013:436307. https://doi.org/10.1155/2013/436307 PMID:24382972

47. Zhao P, Zhang Z. TNF- $\alpha$ promotes colon cancer cell migration and invasion by upregulating TROP-2. Oncol Lett. 2018; 15:3820-7. https://doi.org/10.3892/ol.2018.7735 PMID:29467899

48. Ye X, Wang R, Bhattacharya R, Boulbes DR, Fan F, Xia L, Adoni $\mathrm{H}$, Ajami NJ, Wong MC, Smith DP, Petrosino JF, Venable S, Qiao W, et al. Fusobacterium Nucleatum
Subspecies Animalis Influences Proinflammatory Cytokine Expression and Monocyte Activation in Human Colorectal Tumors. Cancer Prev Res (Phila). 2017; 10:398-409.

https://doi.org/10.1158/1940-6207.CAPR-16-0178 PMID:28483840

49. Sceneay J, Chow MT, Chen A, Halse HM, Wong CS, Andrews DM, Sloan EK, Parker BS, Bowtell DD, Smyth MJ, Möller A. Primary tumor hypoxia recruits CD11b+/Ly6Cmed/Ly6G+ immune suppressor cells and compromises NK cell cytotoxicity in the premetastatic niche. Cancer Res. 2012; 72:3906-11.

https://doi.org/10.1158/0008-5472.CAN-11-3873 PMID:22751463

50. Wang D, Sun H, Wei J, Cen B, DuBois RN. CXCL1 Is Critical for Premetastatic Niche Formation and Metastasis in Colorectal Cancer. Cancer Res. 2017; 77:3655-65.

https://doi.org/10.1158/0008-5472.CAN-16-3199 PMID:28455419

51. Moretta L, Ciccone E, Mingari MC, Biassoni R, Moretta A. Human natural killer cells: origin, clonality, specificity, and receptors. Adv Immunol. 1994; 55:341-80.

https://doi.org/10.1016/s0065-2776(08)60513-1 PMID:7508176

52. Bashir A, Miskeen AY, Hazari YM, Asrafuzzaman S, Fazili KM. Fusobacterium nucleatum, inflammation, and immunity: the fire within human gut. Tumour Biol. 2016; 37:2805-10.

https://doi.org/10.1007/s13277-015-4724-0 PMID:26718210

53. Galon J, Mlecnik B, Bindea G, Angell HK, Berger A, Lagorce C, Lugli A, Zlobec I, Hartmann A, Bifulco C, Nagtegaal ID, Palmqvist R, Masucci GV, et al. Towards the introduction of the 'Immunoscore' in the classification of malignant tumours. J Pathol. 2014; 232:199-209.

https://doi.org/10.1002/path.4287 PMID:24122236

54. Lee JC, Mehdizadeh S, Smith J, Young A, Mufazalov IA, Mowery CT, Daud A, Bluestone JA. Regulatory T cell control of systemic immunity and immunotherapy response in liver metastasis. Sci Immunol. 2020; 5:eaba0759.

https://doi.org/10.1126/sciimmunol.aba0759 PMID:33008914

55. Niccolai E, Ricci F, Russo E, Nannini G, Emmi G, Taddei A, Ringressi MN, Melli F, Miloeva M, Cianchi F, Bechi P, Prisco D, Amedei A. The Different Functional Distribution of "Not Effector" T Cells (Treg/Tnull) in Colorectal Cancer. Front Immunol. 2017; 8:1900.

https://doi.org/10.3389/fimmu.2017.01900 PMID:29375559 
56. Amicarella F, Muraro MG, Hirt C, Cremonesi E, Padovan E, Mele V, Governa V, Han J, Huber X, Droeser RA, Zuber M, Adamina M, Bolli $M$, et al. Dual role of tumour-infiltrating $T$ helper 17 cells in human colorectal cancer. Gut. 2017; 66:692-704.

https://doi.org/10.1136/gutjnl-2015-310016 PMID:26719303

57. Sharp SP, Avram D, Stain SC, Lee EC. Local and systemic Th17 immune response associated with advanced stage colon cancer. J Surg Res. 2017; 208:180-6.

https://doi.org/10.1016/j.jss.2016.09.038

PMID:27993206

58. Wang D, Yu W, Lian J, Wu Q, Liu S, Yang L, Li F, Huang L, Chen X, Zhang Z, Li A, Liu J, Sun Z, et al. Th17 cells inhibit $\mathrm{CD}^{+} \mathrm{T}$ cell migration by systematically downregulating CXCR3 expression via IL-17A/STAT3 in advanced-stage colorectal cancer patients. J Hematol Oncol. 2020; 13:68.

https://doi.org/10.1186/s13045-020-00897-z

PMID:32503584

59. Zou W, Restifo NP. T(H)17 cells in tumour immunity and immunotherapy. Nat Rev Immunol. 2010; 10:248-56.

https://doi.org/10.1038/nri2742 PMID:20336152

60. Ling L, Zhao $P$, Yan G, Chen $M$, Zhang $T$, Wang L, Jiang Y. The frequency of Th17 and Th22 cells in patients with colorectal cancer at pre-operation and postoperation. Immunol Invest. 2015; 44:56-69. https://doi.org/10.3109/08820139.2014.936445 PMID:25026244

61. Flemer B, Lynch DB, Brown JM, Jeffery IB, Ryan FJ, Claesson MJ, O'Riordain M, Shanahan F, O'Toole PW. Tumour-associated and non-tumour-associated microbiota in colorectal cancer. Gut. 2017; 66:633-43. https://doi.org/10.1136/gutjnl-2015-309595 PMID:26992426

62. Tjalsma $H$, Boleij A, Marchesi JR, Dutilh BE. A bacterial driver-passenger model for colorectal cancer: beyond the usual suspects. Nat Rev Microbiol. 2012; 10:575-82.

https://doi.org/10.1038/nrmicro2819

PMID:22728587

63. Zhang Z, Cao H, Song N, Zhang L, Cao Y, Tai J. Longterm hexavalent chromium exposure facilitates colorectal cancer in mice associated with changes in gut microbiota composition. Food Chem Toxicol. 2020; 138:111237.

https://doi.org/10.1016/j.fct.2020.111237

PMID:32145354

64. Giuliani C. The Flavonoid Quercetin Induces AP-1 Activation in FRTL-5 Thyroid Cells. Antioxidants (Basel). 2019; 8:112. https://doi.org/10.3390/antiox8050112

PMID:31035637

65. Liu Y, Li H, Ye N, Luo CJ, Hu YY, Wu H, Gong JP. NonCirrhotic Liver is Associated with Poor Prognosis of Hepatocellular Carcinoma: A Literature Review. Med Sci Monit. 2019; 25:6615-23.

https://doi.org/10.12659/MSM.915722 PMID:31479436

66. Trevisani F, Frigerio M, Santi V, Grignaschi A, Bernardi M. Hepatocellular carcinoma in non-cirrhotic liver: a reappraisal. Dig Liver Dis. 2010; 42:341-7. https://doi.org/10.1016/i.dld.2009.09.002 PMID:19828388

67. Loo TM, Kamachi F, Watanabe Y, Yoshimoto S, Kanda H, Arai Y, Nakajima-Takagi Y, Iwama A, Koga T, Sugimoto $Y$, Ozawa $T$, Nakamura $M$, Kumagai $M$, et al. Gut Microbiota Promotes Obesity-Associated Liver Cancer through $\mathrm{PGE}_{2}$-Mediated Suppression of Antitumor Immunity. Cancer Discov. 2017; 7:522-38. https://doi.org/10.1158/2159-8290.CD-16-0932 PMID:28202625

68. Hendrikx T, Schnabl B. Indoles: metabolites produced by intestinal bacteria capable of controlling liver disease manifestation. J Intern Med. 2019; 286:32-40. https://doi.org/10.1111/joim.12892

PMID:30873652

69. Hayes CL, Dong J, Galipeau HJ, Jury J, McCarville J, Huang $X$, Wang $X Y$, Naidoo A, Anbazhagan AN, Libertucci J, Sheridan C, Dudeja PK, Bowdish DM, et al. Commensal microbiota induces colonic barrier structure and functions that contribute to homeostasis. Sci Rep. 2018; 8:14184. https://doi.org/10.1038/s41598-018-32366-6 PMID:30242285

70. Li R, Zhou R, Wang H, Li W, Pan M, Yao X, Zhan W, Yang $S$, Xu L, Ding Y, Zhao L. Gut microbiota-stimulated cathepsin $\mathrm{K}$ secretion mediates TLR4-dependent M2 macrophage polarization and promotes tumor metastasis in colorectal cancer. Cell Death Differ. 2019; 26:2447-63.

https://doi.org/10.1038/s41418-019-0312-y PMID:30850734

71. Safari Z, Gérard P. The links between the gut microbiome and non-alcoholic fatty liver disease (NAFLD). Cell Mol Life Sci. 2019; 76:1541-58. https://doi.org/10.1007/s00018-019-03011-w PMID:30683985

72. Li B, Selmi C, Tang R, Gershwin ME, Ma X. The microbiome and autoimmunity: a paradigm from the gut-liver axis. Cell Mol Immunol. 2018; 15:595-609. https://doi.org/10.1038/cmi.2018.7 PMID:29706647 
73. Kyriakopoulos A. The microbiome, its molecular mechanisms and its potential as a therapeutic strategy against colorectal carcinogenesis (Review). 2019.

74. Furusawa Y, Obata Y, Fukuda S, Endo TA, Nakato G, Takahashi D, Nakanishi Y, Uetake C, Kato K, Kato T, Takahashi M, Fukuda NN, Murakami S, et al. Commensal microbe-derived butyrate induces the differentiation of colonic regulatory $T$ cells. Nature. 2013; 504:446-50. https://doi.org/10.1038/nature12721 PMID:24226770

75. Tilg $\mathrm{H}$, Cani PD, Mayer EA. Gut microbiome and liver diseases. Gut. 2016; 65:2035-44.

https://doi.org/10.1136/gutjnl-2016-312729 PMID:27802157

76. Shi W, Wang $Y$, Zhang C, Jin H, Zeng Z, Wei L, Tian Y, Zhang D, Sun G. Isolation and purification of immune cells from the liver. Int Immunopharmacol. 2020; 85:106632.

https://doi.org/10.1016/i.intimp.2020.106632 PMID: $\underline{32470880}$
77. Caporaso JG, Kuczynski J, Stombaugh J, Bittinger K, Bushman FD, Costello EK, Fierer N, Peña AG, Goodrich JK, Gordon JI, Huttley GA, Kelley ST, Knights D, et al. QIIME allows analysis of high-throughput community sequencing data. Nat Methods. 2010; 7:335-6.

https://doi.org/10.1038/nmeth.f.303

PMID:20383131

78. Quast C, Pruesse E, Yilmaz P, Gerken J, Schweer T, Yarza P, Peplies J, Glöckner FO. The SILVA ribosomal RNA gene database project: improved data processing and web-based tools. Nucleic Acids Res. 2013; 41:D590-6.

https://doi.org/10.1093/nar/gks1219

PMID:23193283

79. Klindworth A, Pruesse E, Schweer T, Peplies J, Quast C, Horn M, Glöckner FO. Evaluation of general 16S ribosomal RNA gene PCR primers for classical and nextgeneration sequencing-based diversity studies. Nucleic Acids Res. 2013; 41:e1.

https://doi.org/10.1093/nar/gks808 PMID:22933715 